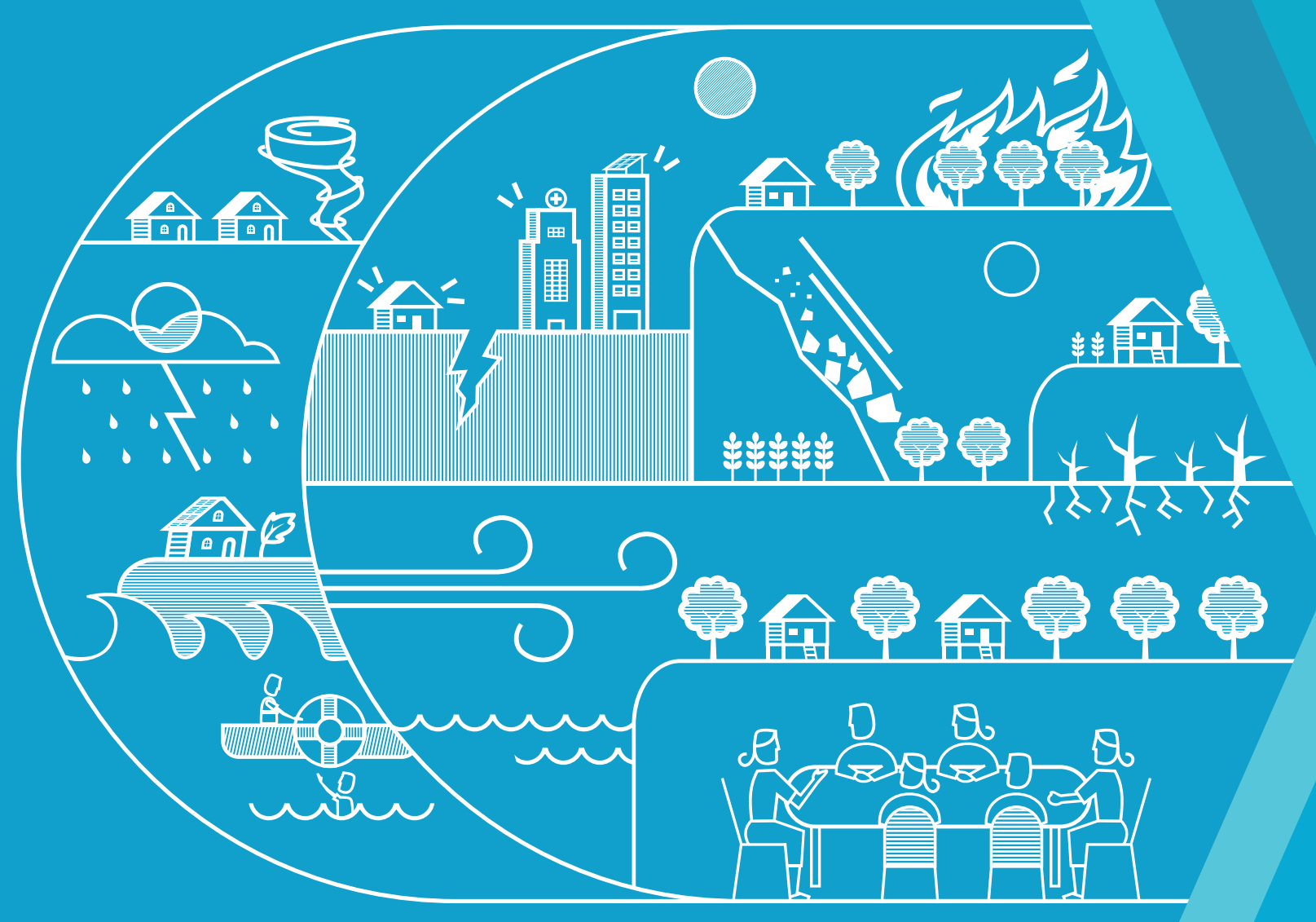

\title{
DISASTER RISK ASSESSMENT FOR PROJECT PREPARATION
} A Practical Guide 


\section{DISASTER RISK ASSESSMENT FOR PROJECT PREPARATION}

A Practical Guide NOVEMBER 2017 


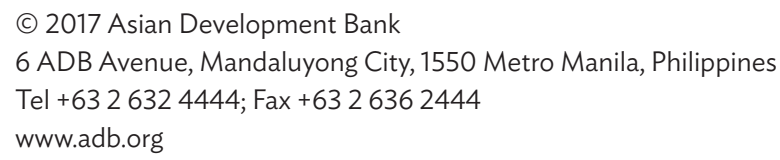

The views expressed in this publication are those of the authors and do not necessarily reflect the views and policies of the Asian Development Bank (ADB) or its Board of Governors or the governments they represent.

ADB does not guarantee the accuracy of the data included in this publication and accepts no responsibility for any consequence of their use. The mention of specific companies or products of manufacturers does not imply that they are endorsed or recommended by ADB in preference to others of a similar nature that are not mentioned.

By making any designation of or reference to a particular territory or geographic area, or by using the term "country" in this document, $A D B$ does not intend to make any judgments as to the legal or other status of any territory or area.

This work is available under the Creative Commons Attribution 3.0 IGO license (CC BY 3.0 IGO)

https://creativecommons.org/licenses/by/3.0/igo/. By using the content of this publication, you agree to be bound by the terms of this license. For attribution, translations, adaptations, and permissions, please read the provisions and terms of use at https://www.adb.org/terms-use\#openaccess

This CC license does not apply to non-ADB copyright materials in this publication. If the material is attributed to another source, please contact the copyright owner or publisher of that source for permission to reproduce it. ADB cannot be held liable for any claims that arise as a result of your use of the material.

Please contact pubsmarketing@adb.org if you have questions or comments with respect to content, or if you wish to obtain copyright permission for your intended use that does not fall within these terms, or for permission to use the ADB logo.

Notes:

In this publication, "\$” refers to US dollars.

Corrigenda to ADB publications may be found at http://www.adb.org/publications/corrigenda 


\section{Contents}

Acknowledgments $\quad$ iv

Abbreviations $v$ v

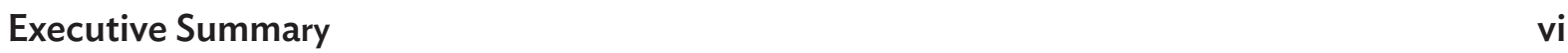

1 Introduction $\quad 1$

A. Rationale for ADB's Engagement in Integrated Disaster Risk Management

B. Past ADB Practice for Incorporating Disaster Risk Information in Project Design

C. Key Objectives and Use of the Practical Guide

$2 \quad$ Preliminary Climate Change and Disaster Risk Screening

A. Climate Change and Disaster Risk Screening in ADB

3 Disaster Risk Assessment: Overview
A. Disaster Risk
B. Disaster Risk Assessments
C. Qualitative vs. Quantitative Disaster Risk Assessments
D. Use of Disaster Risk Assessments for Decision Making

4 Designing Disaster Risk Assessment for ADB's Project Preparation Needs
A. Determining the Scope of the Disaster Risk Assessment
B. Determining the Depth and Type of Disaster Risk Assessments
C. Disaster Risk Assessment Options
D. Integrating Disaster Risk Assessment Aspects into Other Assessments
E. Policy- and Results-Based Loans

$5 \quad$ Addressing Disaster Risk across ADB's Key Sectors
A. Designing and Evaluating Disaster Risk Management Options
B. Case Studies of Sector-Specific Disaster Risk Management Measures

6 Disaster Risk Assessment and ADB's Business Processes
A. Project Identification and Design
B. Monitoring Disaster Risk and Disaster Risk Management

\section{Glossary}

References

Further Reading

Appendixes

1. Disaster Risk Assessment: Step-by-Step Guide

2. Spatial Data Requirements for Disaster Risk Assessment

3. Lead Disaster Risk Assessment Questions Focusing on Natural Hazards and Exposure

4. Lead Disaster Risk Assessment Questions Focusing on Community Vulnerability

5. Examples of Structural and Nonstructural Disaster Risk Management Options in ADB's Key Sectors

6. List of Sample Disaster Risk Management Indicators 


\section{Acknowledgments}

This document was prepared under the Asian Development Bank (ADB) regional technical assistance project Development of Guidance Materials and Screening Tools for Incorporating Disaster Risk Concerns in Country Partnership Strategy and Project Preparation (TA8752-REG). The project was implemented under the overall guidance of Charlotte Benson, principal disaster risk management specialist, Sustainable Development and Climate Change Department (SDCC). This guidance document was prepared by Alexandra Galperin (consultant).

The document benefited significantly from comments received from the following ADB staff: Maria Pia Ancora, climate change specialist, East Asia Department (EARD); Ashok Bhargava, director, EARD; Mary Jane David, senior public management officer (Disaster Risk Management), SDCC; Anthony Jude, former director, South Asia Department (SARD); Manfred Kiefer, energy specialist, Southeast Asia Department (SERD); Cinzia Losenno, former senior climate change specialist, SDCC; Emma Marsden, senior environment specialist, SDCC; Andrew Parker, former principal social sector economist, Pacific Department; Zarah Caoile Pilapil, associate environment officer, SARD; Pia Reyes, water resources officer, SDCC; Nathan Rive, climate change specialist, Central and West Asia Department (CWRD); Vidhisha Samarasekara, former senior climate change specialist, SARD; Arghya Sinha Roy, senior disaster risk management dpecialist, SDCC; Ancha Srinivasan, principal climate change specialist, SERD; Samuel Tumiwa, principal energy specialist, CWRD; Sasank Vermuri, urban development specialist, SDCC; and Lloyd Wright, senior transport specialist, SDCC.

Grendel Saldevar-Perez, senior operations assistant, SDCC, skillfully managed budgetary and contractual matters, and provided invaluable administrative support. The document was proofread by Ricardo Chan and Kae Sugawara and the layout designed by Rocilyn Locsin Laccay. 


\section{Abbreviations}

$\begin{array}{ll}\text { ADB } & \text { Asian Development Bank } \\ \text { ASTER } & \text { Advanced Spaceborne Thermal Emission and Reflection Radiometer } \\ \text { CRVA } & \text { climate risk and vulnerability assessment } \\ \text { DMC } & \text { developing member country } \\ \text { DMF } & \text { design and monitoring framework } \\ \text { DRA } & \text { disaster risk assessment } \\ \text { DRM } & \text { disaster risk management } \\ \text { DRR } & \text { disaster risk reduction } \\ \text { EIA } & \text { environmental impact assessment } \\ \text { EMP } & \text { environmental management plan } \\ \text { GIS } & \text { geographic information system } \\ \text { IPCC } & \text { Intergovernmental Panel on Climate Change } \\ \text { MODIS } & \text { Moderate Resolution Imaging Spectroradiometer } \\ \text { Open DRI } & \text { Open Data for Resilience Initiative } \\ \text { PPTA } & \text { project preparatory technical assistance } \\ \text { RAMP } & \text { risk assessment management plan } \\ \text { REA } & \text { rapid environmental assessment }\end{array}$




\section{Executive Summary}

Disasters pose a significant threat to the sustainability of development projects and investments. At the same time, many development actions provide opportunities to strengthen disaster resilience. Reflecting this, the integration of disaster risk reduction into development forms one of three key principles of the Operational Plan for Integrated Disaster Risk Management, 2014-2020 of the Asian Development Bank $(A D B)$.

This document is intended to support the application of this principle by providing ADB project officers sufficient technical advice to plan and oversee disaster risk assessments (DRAs). These assessments provide a basis for integrating disaster risk considerations into the design and implementation of individual projects. The document should be consulted in cases where preliminary climate change and disaster risk screening indicates that a more detailed DRA would be beneficial, helping to ensure that disaster risks are properly identified and measures taken to reduce them where necessary. The document is also relevant in undertaking disaster risk components of climate risk and vulnerability assessments.

The document begins by outlining the rationale for integrating disaster risk management (DRM) into ADB projects. ADB's preliminary project disaster risk screening arrangements are then described, followed by an overview of DRA approaches and methodologies for projects warranting more in-depth analysis. The succeeding sections focus on the design of individual DRAs and the application of their results and recommendations, including sector examples of potential DRM actions. The final section covers the integration of DRAs and their recommendations into ADB's project-related business processes and templates.

Six supporting appendixes are provided focusing on (i) more detailed technical guidance on data collection and the analytical steps of a DRA, covering natural hazard assessment, the identification of exposed assets, vulnerability analysis, and integration of the strands into a DRA (Appendix 1); (ii) further guidance on spatial data requirements, key sources, and computer applications for natural hazard, exposure, vulnerability, and loss data are provided (Appendix 2); (iii) checklists on lead DRA questions (Appendixes 3 and 4); (iv) examples of disaster-risk-informed interventions specific to ADB's key sectors (Appendix 5); and (v) sample DRM indicators (Appendix 6).

The document was prepared as part of a wider capacity development technical assistance project, Development of Guidance Materials and Screening Tools for Incorporating Disaster Risk Concerns in Country Partnership Strategy and Project Preparation, financed by ADB's Technical Assistance Special Fund. ${ }^{1}$ Two companion documents focus on natural hazard data ${ }^{2}$ and country partnership strategies. ${ }^{3}$ The technical assistance also supports the modification of AWARE, an interactive online project climate risk screening tool used by ADB to integrate geological hazards, enhance weather-related hazard components, and augment screening output recommendations regarding DRM.

ADB. 2014. Technical Assistance for Development of Guidance Materials and Screening Tools for Incorporating Disaster Risk Concerns in Country Partnership Strategy and Project Preparation. Manila (TA 8752-REG).

2 ADB. 2017. Natural Hazard Data: A Practical Guide. Manila.

3 ADB. 2017. Disaster Risk Management and Country Partnership Strategies: A Practical Guide. Manila. 


\section{Introduction}

\section{A. Rationale for ADB's Engagement in Integrated Disaster Risk Management}

Natural hazards pose a significant threat to development projects and the achievement of national and regional development goals in Asia and the Pacific. Many countries in the region experience both hydrometeorological, or extreme weather, and geophysical hazards. Moreover, the region experiences a disproportionate share of global human and economic impacts relative to population and gross domestic product.

Over the period 2007-2016, extreme weather events such as floods, droughts, and tropical cyclones have caused around 216,245 fatalities, affected 1.5 billion people, and resulted in direct physical damage totaling $\$ 373$ billion, equivalent to $\$ 102$ million per day, in the developing member countries (DMCs) of the Asian Development Bank (ADB) alone. ${ }^{1}$ Over the same period, geophysical events such as earthquakes, tsunamis and volcanic eruptions have resulted in around 105,207 fatalities, affected 69 million people, and resulted in direct physical damage totaling $\$ 113$ billion, equivalent to $\$ 31$ million per day, in the DMCs.

Direct physical losses are also increasing, expanding at the same pace as economic growth in ADB's DMCs. This trend of rising losses is expected to continue at least over the next few decades, reflecting the increasing accumulation of disaster risk. Rising disaster losses partly reflect increases in exposure and vulnerability to natural hazards as countries expand and develop with insufficient regard to disaster risk. Climate change threatens to exacerbate the trend of rising disaster losses. Evidence is already beginning to suggest that weather is changing, according to the latest Intergovernmental Panel on Climate Change (IPCC) reports. By 2060, an estimated 729 million-983 million people will be living in low-elevation coastal zones in Asia (Neumann et al. 2015).

Disaster risk therefore requires due consideration in both country programming and project design and implementation. ADB's Strategy 2020 (ADB 2008) recognizes the considerable challenges that natural hazards pose to development in Asia and the Pacific and identifies disaster and emergency assistance as one of ADB's other areas of operations. The Midterm Review of Strategy 2020 re-emphasizes the importance of strengthening disaster resilience. ADB's 2004 Disaster and Emergency Assistance Policy lays out key principles for ADB's engagement in disaster risk management (DRM) (ADB 2004). The Operational Plan for Integrated Disaster Risk Management, 2014-2020 (ADB 2014c) provides operational guidance on the implementation of the Disaster and Emergency Assistance Policy, emphasizing in particular the integration of DRM into development.

Such integration rests upon an adequate disaster risk screening and assessment process that provides the information needed to protect ADB investments against natural hazards, including a better understanding of the levels of disaster risk as well as physical attributes, location, and size. More ambitiously, such assessments can help steer development investments toward increasing the resilience of exposed and vulnerable communities, for instance by helping diversify income sources or improving access to public services.

\footnotetext{
Figures based on data extracted from EM-DAT: The OFDA/CRED International Disaster Database, www.emdat.be, Université Catholique de Louvain, Brussels.
} 


\section{B. Past ADB Practice for Incorporating Disaster Risk Information in Project Design}

The foundation of effective DRM is information and assessment. ADB considers disaster risk during project design through the preliminary climate change and disaster risk checking and screening process (section 2.A). This process serves to determine climate change and disaster risk and alert project officers to projects requiring more detailed assessment. If this preliminary screening process identifies medium or high climate change risk, this risk is further explored through a climate risk and vulnerability assessment (CRVA). CRVAs include further assessment of extreme weather events if relevant. Indeed, reducing the risks associated with extreme weather events is a substantial component of both DRM and climate change adaptation. However, there are distinct differences between CRVAs and DRAs (Table 1). CRVAs do not incorporate full DRAs and, in particular, do not take account of geophysical hazards. These differences imply that ADB's past screening process has not supported the full, systematic consideration of disaster risk in the design of ADB projects. Table 1: Climate Change Risk and Vulnerability Assessment and Disaster Risk Assessment:
Major Commonalities and Differences

\begin{tabular}{|c|c|}
\hline $\begin{array}{l}\text { Climate Change Risk and Vulnerability } \\
\text { Assessment }\end{array}$ & Disaster Risk Assessment \\
\hline \multicolumn{2}{|c|}{ Purpose } \\
\hline $\begin{array}{l}\text { Identifies impact of changes in mean climatic } \\
\text { conditions (i.e., temperature, precipitation, and } \\
\text { wind speed) and sea levels, including impacts on the } \\
\text { frequency and intensity of extreme weather events, } \\
\text { to identify a range of climate change adaptation } \\
\text { options (including DRM). }\end{array}$ & $\begin{array}{l}\text { Analyzes natural hazards, including geophysical } \\
\text { hazards, and associated disaster risk in depth and } \\
\text { recommends potential DRM actions as necessary. }\end{array}$ \\
\hline \multicolumn{2}{|c|}{ Assessors } \\
\hline $\begin{array}{l}\text { Carried out by experts in climate change modeling, } \\
\text { climate change impact assessments, climate change } \\
\text { adaptation, and economic costs of climate change. }\end{array}$ & $\begin{array}{l}\text { Carried out by experts in natural hazard and disaster } \\
\text { risk modeling (geophysicists, geologists, hydrologists, } \\
\text { etc.), vulnerability and disaster impact assessments } \\
\text { (social scientists, structural engineers), disaster } \\
\text { risk reduction interventions, and the economics of } \\
\text { disaster risk management. }\end{array}$ \\
\hline \multicolumn{2}{|c|}{ Coverage } \\
\hline
\end{tabular}

In the context of natural hazards, deals with extreme weather events only.
Covers all types of natural hazard, including geophysical hazards.

DRM $=$ disaster risk management

Source: ADB.

Other project preparatory processes have filled this gap to some degree. The exposure of ADB projects to particular types of natural hazard, in some cases including stand-alone multihazard DRAs, has been incorporated into some environmental impact assessments. DRAs pertaining to specific types of natural hazard have also been included in some instances in other technical assessments such as hydrological assessments. However, ADB has lacked a consistent approach to in-depth DRA. Moreover, the quality of these assessments has depended on the knowledge and background of the individuals concerned, including both project officers and consultants. 


\section{Key Objectives and Use of the Practical Guide}

This practical guide addresses the need to promote a more strategic and homogeneous approach to DRA at $A D B$, integrated as relevant with the climate risk assessment process. It is intended to provide project officers with sufficient information to plan and oversee DRAs, in turn providing a basis for integrating disaster risk considerations into the design and implementation of individual projects where relevant. The practical guide should be consulted in cases where preliminary climate change and disaster risk screening indicates that disaster risk is medium or high, helping to ensure that disaster risks are properly identified and measures taken to reduce them where necessary.

The practical guide provides guidance to project officers on concepts and good practice in DRA and on the identification of suitable and efficient ways to include DRAs in project design processes. It includes information on the key elements of high-resolution, in-depth DRAs and on possible abbreviated processes in cases where time or resources are limited. The document cover types of output, the application of findings in project planning, and, more broadly, the integration of DRAs into ADB's project-related business processes.

The practical guide covers the three main phases of ADB's project cycle: project identification, project design, and project implementation and monitoring, as indicated in Figure 1.

Figure 1: Three Key Sections of the Practical Guide

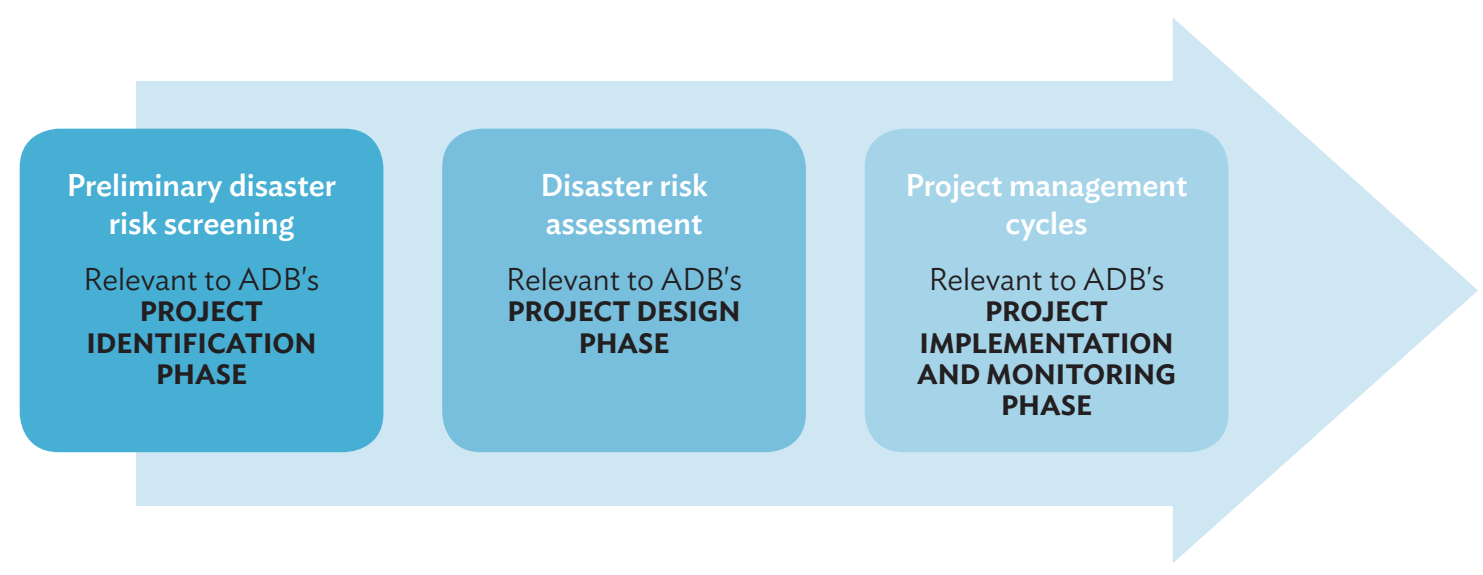

$\mathrm{ADB}=$ Asian Development Bank Source: ADB.

Section 2 deals with the project identification phase, outlining ADB's preliminary disaster risk screening procedures. Sections 3, 4, and 5 are relevant to ADB's project design phase. They deal with all stages of DRAs and the application of risk information across the sectors of ADB's work. Users are provided with the necessary information to start planning abbreviated or full DRAs, write terms of reference, and review related technical proposals. Section 5 also discusses measures to address disaster risk in specific sectors, reflecting the ultimate purpose of assessment to incorporate appropriate disaster risk reduction (DRR) elements in project design where necessary. Finally, section 6 focuses on DRAs in the context of ADB's business processes, in particular on DRM measures related to monitoring and evaluation. 


\section{Preliminary Climate Change and Disaster Risk Screening}

\section{A. Climate Change and Disaster Risk Screening in ADB}

$A D B$ examines a range of different aspects of a project during the project identification and concept phase. Climate change and disaster risks are initially covered through the rapid environmental assessment (REA). This includes a specific section on community health and safety dealing with natural hazards. ${ }^{2}$ Results feed into the environmental safeguard classification and overall quality assurance process. If the project is found to score an "A" or "B" in the safeguard categorization, closer environmental scrutiny is required.

ADB's REA form also contains a checklist for preliminary climate change and disaster risk screening. Among other issues, this one-page checklist looks at the possible impact of extreme hazard events on a project (Figure 2). If a project is found to have a medium to high climate change or disaster risk according to this preliminary checklist, it should undergo more detailed disaster risk screening, for instance using the AWARE for Projects tool (Box 1$)^{3}$ or other web-based open-access tools (Appendix 2).

Figure 2: Disaster Risk Screening in ADB

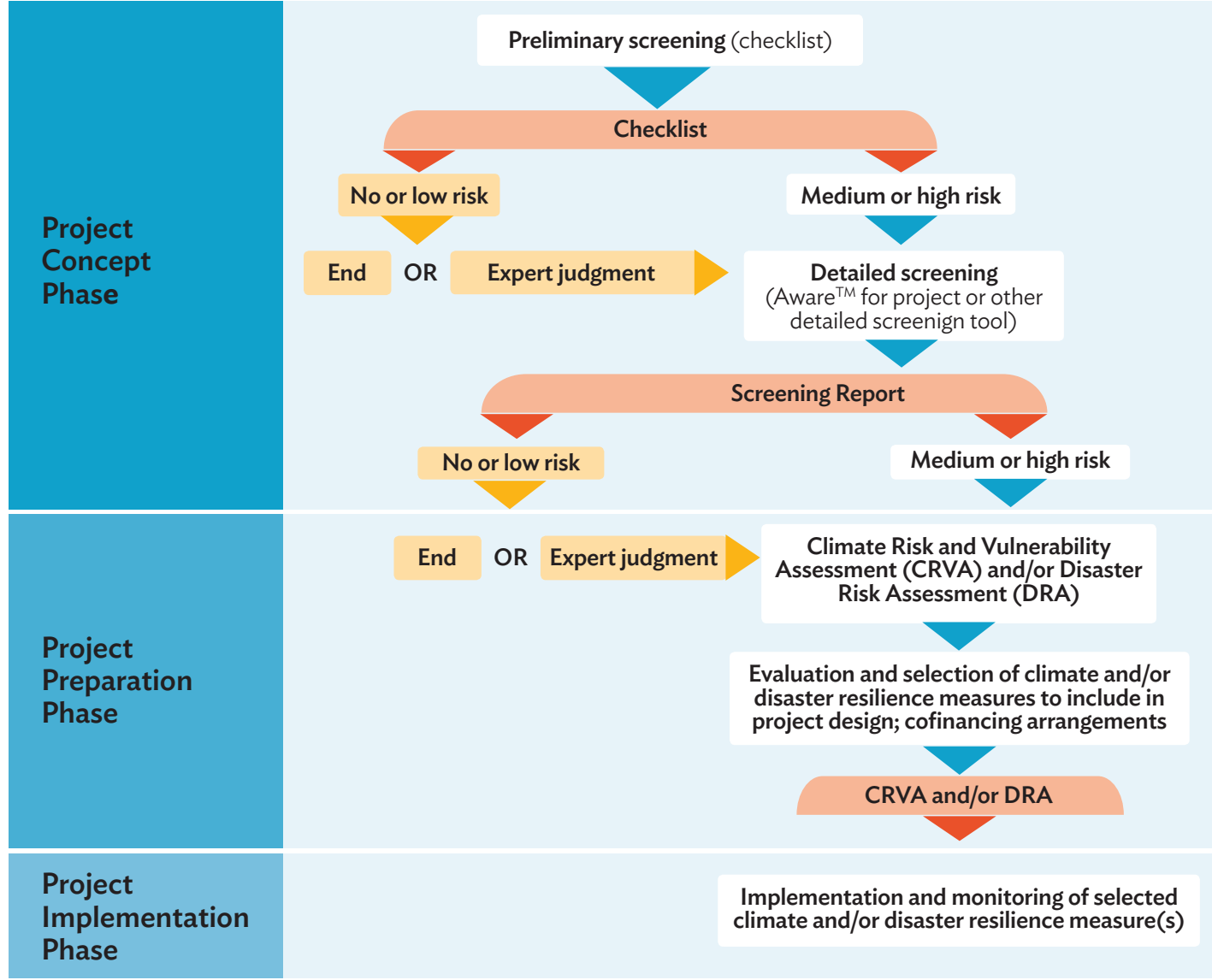

Source: Adapted from ADB (2014b).

2 The REA refers to these as "community safety risks due to both accidental and natural hazards."

3 The enhanced version of the AWARE tool introduced in 2017 covers geophysical hazards as well as extreme weather events. 
AWARE is a web-based, commercial tool that facilitates a rapid risk screening of projects and project components focusing on climate change risk and exposure to natural hazards. The tool also provides sector-specific commentary on issues that require further attention and assessment. The tool has been modified to match the project sectors and subsectors of the Asian Development Bank (ADB). An updated version incorporating geophysical hazards and enhanced assessment of near-term hydrometeorological hazards was released in May 2017.

AWARE is designed to be user-friendly and relatively rapid and is intended as a preliminary screening tool. The tool does not require expert knowledge of climate change or disaster risk. It can be used in two modes: rapid and full. A rapid mode assessment only requires the user to identify the name of the project, the ADB project sector, and subsectors; to provide the project location; and to indicate if the area is coastal. The tool then generates an assessment of the risk level (low, medium, or high) for 16 variables in a spidergram contained within a standardized report. The full mode requires the user to also answer six questions regarding any required modifications to the project design in order to provide the expected services over the life of the project.

Source: ADB

A low risk score in the AWARE tool will normally not require any further investigation. However, in case of uncertainties (e.g., due to data deficiencies), further expert consultation may need to be conducted. ${ }^{4}$ If a project or one of its subcomponents receives a medium or high risk score, a more in-depth assessment is required during the project preparatory technical assistance (PPTA).

The use of CRVAs and DRAs should be determined in combination, taking into account the results of the climate change and disaster risk screening. There are several options, depending on these results:

- If climate change risk is medium or high but disaster risk is low, a CRVA is sufficient.

- If disaster risk is medium or high but climate change risk is low, a DRA is sufficient.

- If climate change and hydrometeorological hazard risk is medium or high but geophysical hazard risk is low, an expanded CRVA, covering extreme events in the near term as well as consequences of climate change, is sufficient.

- If geophysical hazards are medium or high but climate change and extreme weather risk are low, a DRA, focusing on geophysical hazards, is sufficient. Alternatively, for infrastructure projects, it may be sufficient to ensure that geophysical risk is incorporated into detailed technical design.

- If both climate change risk and disaster risks are medium or high, joint or separate CRVAs and DRAs may be required. Either way, the two teams should work together closely to take advantage of DRM expertise in reducing the impact of extreme weather events and to ensure the full incorporation of projected climate change conditions into the analysis of extreme weather hazards and the design of appropriate DRM measures.

Depending on project context and the required scope and depth, a DRA can be conducted as a standalone exercise or integrated into the environmental impact assessment (EIA) or initial environmental examination (section 4.B for more details on the depth and type of DRA).

\footnotetext{
4 Experts may include hazard specialists or other relevant technical experts who could weigh in on sector-specific exposure and vulnerability issues.
} 


\section{Disaster Risk Assessment: Overview}

\section{A. Disaster Risk}

Figure 3: Three Components of Disaster Risk

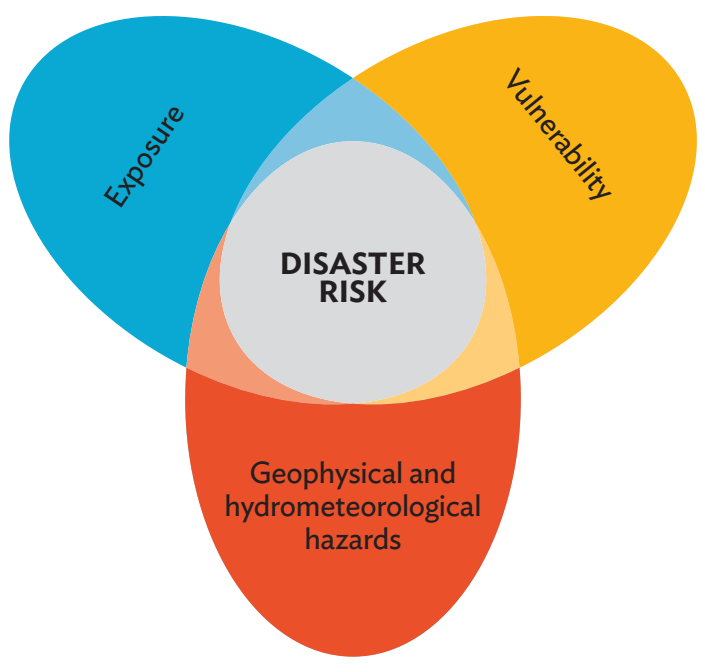

Source: ADB.

Disaster risk is a function of the probability of occurrence of a natural hazard of varying intensity (i.e., physical strength) in a particular location, $p\left(h_{i}\right)$; the people and physical assets situated in that location and therefore exposed to the natural hazard, $e$; and the level of vulnerability of those exposed people and physical assets to that natural hazard, $v$ (Figure 3 ). This relationship can be expressed mathematically as

$$
\text { Disaster risk }=f\left(p\left(h_{i}\right), e, v\right)
$$

Natural hazards describe potentially occurring natural events, comprising geophysical hazards, such as earthquakes, tsunamis, and volcanic eruptions, as well as hydrometeorological or extreme weather hazards, such as floods, droughts, and tropical cyclones. ${ }^{5,6}$ Landslides can be triggered both by geological hazards and by extreme weather events. For the purpose of DRAs, the concept of a natural hazard is understood to have three main interrelated characteristics: intensity (the physical strength of a hazard), frequency (the probability of occurrence), and location.

The second component of the disaster risk equation is the exposure of an element at risk-that is, the degree of possible physical contact between a community, livelihood, or asset and a potentially damaging natural hazard event (for instance, structures or settlements located in floodplains).

5 See the companion document on Natural Hazard Data: A Practical Guide for a fuller discussion of different types of natural hazard.

6 Tropical cyclone is the generic term for hurricanes, cyclones, and typhoons. All three terms refer to the same weather phenomenon, the difference in term reflecting the origin of a particular event. Storms originating in the Atlantic and Northeast Pacific are referred to as hurricanes; storms originating in the Northwest Pacific are referred to as typhoons; and storms originating in the South Pacific and Indian Ocean are referred to as cyclones. 
Vulnerability relates to the physical, social, economic, and environmental conditions of a community, livelihood, or a particular asset and its propensity or predisposition to be adversely affected by a natural hazard event. Vulnerability can increase risk from even relatively moderate natural hazards. For instance, unreinforced adobe structures in combination with moderate but frequent seismic activity can result in high levels of disaster risk, translating into substantial loss and damage over time. In other words, low levels of hazard intensity do not necessarily indicate low levels of risk if exposure and vulnerability are high. The conditions that generate vulnerability overlap significantly with the various facets of poverty, such as low income and lack of access to services and information.

Disaster resilience is the ability of a system, community, or society exposed to hazards to resist, absorb, accommodate, adapt to, transform, and recover from the effects of a hazard in a timely and efficient manner. Resilience relates to physical, social, and economic capacities and the natural environment. The contrasting concept of vulnerability describes a lack or weakness of characteristics needed to be resilient (UNISDR 2017).

Since both vulnerability and exposure are dynamic, socially defined, and geographically specific, they are best analyzed and measured at the local level. Local development processes that do not factor in disaster risks can increase levels of vulnerability and exposure.

\section{B. Disaster Risk Assessments}

A DRA identifies and analyzes the types, intensities, and probabilities of natural hazard events and the resulting impact on people, communities, and assets with a defined spatial location.7 The foregoing disaster risk equation provides the basis for this assessment: a DRA estimates risk by analyzing hazard characteristics, elements at risk, and the vulnerability of these elements. The resulting knowledge provides communities, organizations, and governments with a basis to identify how particular projects or activities contribute to increased or reduced disaster resilience, to prioritize DRM needs, and to inform the design of DRM strategies and actions. Figure 4 illustrates the four main steps in undertaking DRAs, as well as some of the key tools and outputs. Outputs and tools are discussed in greater detail in Appendix 1.

DRAs can be conducted in relation to single and multiple types of natural hazard. Multihazard risk assessments are usually considered best practice as countries typically face a range of types of natural hazard. However, depending upon the focus and scale of the project, in some cases a single hazard assessment may be sufficient. A more detailed discussion of DRA options most relevant to ADB project design is presented in section 4.

7 See Appendix 1 for a more detailed technical guidance on data collection and the analytical steps of a DRA, covering natural hazard assessment, the identification of exposed assets, vulnerability analysis, and integration of the strands into a DRA. 
STEP 1

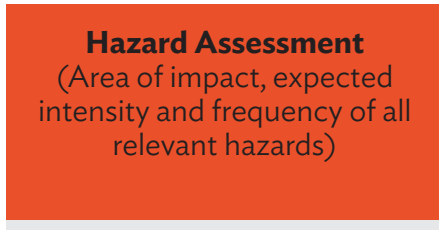

Review historical hazard records and scientific data

Review projections/ scenario of climate change impacts on natural hazard frequency and intensity

\section{Outputs:}

Hazard ranking/ modeling/mapping
STEP 2
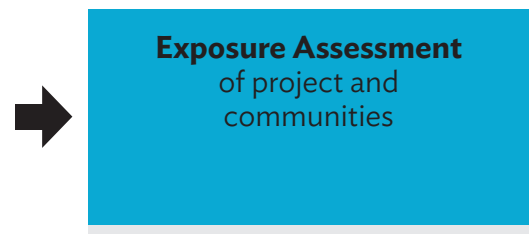

Create inventories of assests (project and relevant community assests) and superimpose with hazard data

\section{Outputs:}

Exposure data/maps of project footprint/ impact area

STEP 4

\section{STEP 3}

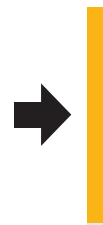

Analyze historical damage data

Undertake engineering and other assessments of asset vulnerability

Develop damage/ loss functions

\section{Outputs:}

Vulnerability data/ functions / maps

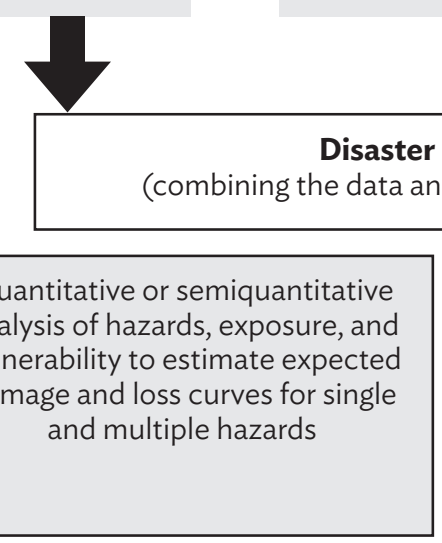

Quantitative or semiquantitative analysis of hazards, exposure, and vulnerability to estimate expected damage and loss curves for single and multiple hazards
Identification and justification of options to reduce and manage disaster risks (adjustments in project design, operations and maintenance regime, additional project components to strengthen community resilience)

Source: ADB.

\section{Qualitative vs. Quantitative Disaster Risk Assessments}

There are a variety of DRA tools and methodologies. Choosing the appropriate one depends on the scale and objectives of the assessment, the level of access to data and technology, available resources (time, expertise, and funds), and stakeholder and end-user priorities and concerns. Methods vary from local participatory assessments using mostly qualitative research tools to highly quantitative national or regional assessments based on statistical and modeling methods (Appendix 1, step 4). However, DRAs do not have to be complicated or time-consuming exercises. Sometimes, the analysis of existing risk information such as hazard maps and disaster loss data may be sufficient to determine if higher design standards are needed (section 4.B).

Many DRAs mix quantitative or semiquantitative methods with a qualitative analysis of causal chains that contribute to the exposure and vulnerability of elements at risk. Quantitative risk assessment uses numerical values to estimate both the likelihood and consequences of natural hazard events and is important, for instance, in the development of disaster insurance instruments and the enhanced fiscal management of disaster risk more broadly. The accuracy of quantitative risk assessments depends on the quality of input data and the validity of applied algorithms and modeling tools (Box 2). Access to 
tested and approved vulnerability functions of elements at risk, such as local building stock, helps ensure a more accurate estimation of damage and loss (Appendix 1, step 4). Developing such functions during the project preparation phase is typically unrealistic, except sometimes in the context of specific stand-alone DRR projects.

\section{Box 2: Investing in Disaster Risk Datasets}

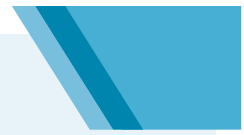

Datasets on hazards, exposure, and vulnerability can be difficult to obtain, hindering the assessment of disaster risk. If disaster risk is perceived to be high but available knowledge is very limited, activities to establish relevant datasets (e.g., vulnerability functions of the local building stock) can potentially be integrated into project design.

Source: ADB.

In the context of PPTA, qualitative and semiquantitative analysis will often be the default option, especially if available data are limited. Qualitative assessments still require numerical data (e.g., data on the intensity of a natural hazard or historical damages and losses) but do not use quantitative methods to compute risk levels (Appendix 1, step 4.1). They are also the preferred approach if it is necessary to engage with stakeholders from different educational and professional backgrounds, such as community groups or politicians. Qualitative DRAs often use semiquantitative methods such as attaching numerical values to descriptive indicators in order to determine the relative likelihood and extent of possible damage and loss. This increases the internal consistency of the analysis and reduces subjectivity.

\section{Use of Disaster Risk Assessments for Decision Making}

The identification of appropriate options to reduce disaster risk is the ultimate purpose of risk-informed planning. In other words, the DRAs discussed in this practical guide seek to facilitate risk-informed decision making regarding where and what to invest in and detailed project design in order to manage disaster risks associated with development projects. Table 2 illustrates investment-centered objectives that are relevant to ADB. DRAs can also be conducted during project implementation, for instance, to inform a financial risk transfer scheme or to design a comprehensive flood risk management or an early warning system. These assessments often require substantive resources and time. 
Table 2: Objectives of Disaster Risk Assessments in the Context of ADB Project Preparation

\section{Objective Example}

To inform the nature and extent

To help assess the proposed siting of a hydropower project of disaster risk in the selection of project sites

To inform the integration of DRM measures into structural design

To inform the integration of nonstructural DRM measures into a project

To inform the design of DRM stand-alone projects
To determine how to strengthen the disaster resilience of transport, energy, or urban infrastructure projects

To determine the potential need for project components such as early warning systems and contingency plans

$\mathrm{ADB}=$ Asian Development Bank, $\mathrm{DRM}=$ disaster risk management

Source: ADB.

There is large variation in terms of the expertise, time, and resources required to generate the risk information needed for the various objectives listed in Table 2. For instance, preparation of a seismic retrofitting project of a school requires extensive data, not only on the natural hazard but also on exposure and vulnerability, to identify and prioritize buildings for support. In contrast, identifying high-risk communities for a participatory flood risk management project subcomponent typically requires less data. More detailed assessments and planning needed to develop individual measures such as communitybased contingency plans will be part of the implementation process. 


\section{Designing Disaster Risk Assessments for ADB's Project Preparation Needs}

\section{A. Determining the Scope of the Disaster Risk Assessment}

Three key questions inform the required scope and complexity of a DRA (and DRA components of CRVAs):

- What natural hazards should the assessment focus on?

- Does the DRA require a single sector or a multisector lens?

- Is it sufficient to focus the DRA on the project site alone or should it cover the larger area of impact of either the project or the natural hazard(s) under investigation?

A project area may be threatened by one or multiple natural hazards. If both screening and desk studies of the project area suggest that an area is only exposed to one type of hazard, say flooding, then a flood risk assessment is sufficient. However, if a range of types of natural hazard of significant magnitude could occur, it is important to conduct a multihazard DRA - that is, the initial hazard analysis needs to identify all relevant types of natural hazard occurring in the project area and their interactions and to take them into account in the DRA. Secondary hazards triggered by other types of hazard should also be considered. For instance, earthquakes can trigger landslides under certain conditions while strong winds may cause coastal flooding.

Multihazard DRAs are complex and potentially costly if they entail a number of types of natural hazard. Different natural hazards may affect different or overlapping geographical areas, have differing probabilities of occurrence at varying levels of intensity, and have different impacts on exposed assets. A multihazard DRA will need to analyze the vulnerability of each exposed asset to each type of natural hazard. However, it is very important to understand the range and impact of all relevant types of natural hazard on a project and communities within its vicinity to ensure the appropriate design of disaster resilient outputs.

It is also considered good practice to look at a wide range of elements at risk and apply a multisector lens to DRAs. The following principles are relevant to decision making on the sector scope of a DRA:

- All external infrastructure and services, such as power supply, communications, and road access, that a project relies on to ensure strong project performance should be considered. This may require expanding the geographical scope of the DRA since relevant infrastructure may be located in a different area and subject to different types and levels of natural hazard. ${ }^{8}$ The DRA should then go on to identify backup sources of key service inputs that should be built into a project to ensure continuity of service delivery provided by the project in the event of a disaster (e.g., sources of backup power for traffic management system communications installed as part of an urban transport project in a high seismic risk area).

- A multisector risk assessment is often particularly relevant for the design of resilient urban or rural development projects that combine a range of sector interventions. ${ }^{9}$ An urban development project, for instance, may include components relating to transportation networks, potable water, drainage and wastewater management, and settlement planning. A DRA needs to look at all of these, both individually and in terms of their potential interaction-for instance, the potential risk of wastewater infiltration into potable water supply in the event of a flood.

\footnotetext{
8 Obviously applying this principle requires using common sense in terms of drawing a line with regard to the territory under investigation.

9 See section 5.B for case studies on multisector risk assessments.
} 
DRAs, just like EIAs, need to look not only at the project site but also to explore any positive or negative impacts of the project, via both its design and operation, on disaster risk in the project impact area, including on communities in the vicinity of the project, as illustrated in Box 3 . These considerations need to inform the territorial scope of a DRA.

\section{Box 3: Built Infrastructure and Flood Risk}

Some types of built infrastructure can significantly increase the risk of flooding. For instance, in road construction, the sealing of large areas with impermeable surfaces will reduce absorption capacity of the landscape and increase rainfall runoff. Even the design of appropriate drainage systems may still alter the local hydrology as rainfall will potentially enter local river networks at greater velocity, increasing risk of flooding for downstream communities. In general, any development that obstructs a waterway and/or reduces floodplain or wetland storage capacity can affect flood risk. Ironically, this also applies to traditional flood defenses such as dikes and embankments as they reduce upstream floodplain storage and increase the volume and speed of water runoff downstream. There are also issues of drainage of floodwaters if flood defenses are breached. Therefore, infrastructure projects such as roads and flood defenses in flood-prone areas and river basins preferably require a careful analysis of flood risk.

Source: ADB.

\section{B. Determining the Depth and Type of Disaster Risk Assessments}

A full-fledged DRA is not always necessary. In some cases, DRAs can focus on a number of key questions and/or can be integrated into other assessments, in particular CRVAs (see section 2.A). Table 3 indicates some key parameters that should be taken into consideration in determining the depth of a DRA.

Table 3: Deciding on the Depth of the Disaster Risk Assessment

Parameter exposure context

Scale of investment (size of project)

Type of project

In-country (DRM) capacity
Details/Indicative Questions

- Preliminary disaster risk screening rating (high/medium/low, as per AWARE or other risk screening tool)

- Small (< $\$ 50$ million), medium ( $\$ 50$ million-400 million) or large $(>\$ 400 \text { million })^{a}$

- Magnitude of potential worst-case consequences of project failure due to a natural hazard

- Explicit disaster resilience goals of the project (all medium-sized and large projects seeking to strengthen disaster resilience as an explicit outcome of the project need to undergo a DRA)

- Level of availability of data on natural hazards, exposure, vulnerability, and disaster risk

- Extent of existence and application of disaster-risk-sensitive land-use plans

- Availability and application of disaster-risk-sensitive design standards and building codes

- DRM capacity of relevant government agencies

DRA = disaster risk assessment, DRM = disaster risk management.

a These figures are only indicative. The size of the national economy should be taken into account to evaluate the relative scale of an investment for individual countries.

Source: ADB 
First and foremost, if the preliminary screening indicates that the disaster risk is low, then a DRA is not necessary. In other cases, natural hazard frequency and intensity, scale of investment, type of project, and DRM capacity and enabling environment need to be weighed carefully to decide on the depth of a DRA. As a rule of thumb, large-scale investment projects in medium- and high-risk areas that cover or impact a large, more densely populated area require greater scrutiny, both because of the potential scale of direct losses and the life safety and socioeconomic consequences. More comprehensive DRAs are also warranted in medium- and high-risk areas for relatively smaller projects if the projects are critical to the functioning of communities (e.g., urban water or electricity) or if the structural failure of project infrastructure as a consequence of a disaster could potentially lead to loss of life (e.g., in the context of the collapse of schools, other public buildings, or water reservoirs). The availability of data on natural hazards, exposure, and vulnerability may also influence the level of depth of an assessment. Legislative and regulatory frameworks governing the use of land and building standards are additionally important. If a country applies strict risk-sensitive land-use plans and disaster-resilient building standards, then those regulations will automatically help guide risk-appropriate project location and design decisions. The Sustainable Development and Climate Change Department can provide further guidance on the scale of assessment required in specific cases.

\section{Disaster Risk Assessment Options}

\section{Disaster Risk Assessment Focusing on Exposure}

For small-scale, targeted investments in infrastructure, such as a short stretch of road or water pipeline, it may be sufficient to focus on the natural hazards to which the investment and the project catchment area are exposed, rather than undertake a detailed DRA. The following are the main steps of such an assessment:

- Gather and analyze data on the intensity and probability of a natural hazards in the project area.

- Map out the intensity and area of impact of significant natural hazard(s).

- Map out the footprint and impact area of the planned structural investments and superimpose on or analyze against natural hazard data and maps, identifying the exposure of the project.

- If necessary, adapt construction designs to enhance resilience.

The so-called design event is a critical concept in engineering assessments as it identifies the maximum intensity of a natural hazard event that a structure is built to withstand during its lifetime. The chosen design event will inform construction design. This is relatively straightforward if risk-sensitive national or local design codes exist. It will also be helpful if ADB has already addressed similar disaster risk in other sites in the country and can mobilize its institutional knowledge. In other cases, more robust and costly site-specific natural hazard and exposure assessments may be necessary, including hazard modeling to identify design events. These assessments require consultants with a track record in conducting sitespecific natural hazard analysis and familiarity with the local context, both in terms of hazards and land use and construction legislation and regulations. The information provided in Appendix 1, steps 1 and 2 on natural hazard and exposure analysis, together with section 5 of the main report on sector-specific DRM options, provides project officers with further tools to formulate relevant disaster-related tasks and deliverables for incorporation into terms of reference for PPTAs as well as some basic information for reviewing technical proposals. 


\section{Disaster Risk Assessments Focusing on Vulnerability Ranking}

In certain scenarios, a focus on vulnerability can generate the disaster-related information required for project design. Vulnerability rankings can be used to identify investment priorities, for instance to identify communities for an urban development or a flood risk management program or to identify priority buildings for a retrofitting or structural rehabilitation project. An example from Armenia is provided in section 5.B.2. Vulnerability ranking requires knowledge and an understanding of the distribution of various types of natural hazard and their maximum intensities in the project area. It is easiest in cases where the project area has relatively uniform levels of hazard and exposure. The following are the main steps of such an assessment:

- Gather natural hazard data and maps and superimpose or analyze against data on assets and communities in the project area to determine exposed assets and people.

- Identify key indicators of vulnerability (physical, social, economic; Appendix 1, step 1.2).

- Analyze the vulnerability of exposed assets or communities using these indicators.

- Rank the vulnerability of assets/communities.

- If time and resources permit, further analyze the dynamics and causes underlying vulnerability and develop DRM options.

There should be a reasonable correlation between selected vulnerability indicators and damage and loss potential, preferably backed up by historical damage data. Original research, such as field surveys or assessments, at the community level may need to be conducted to identify, adapt, or test potential indicators.

\section{Integrating Disaster Risk Assessment Aspects into Other Assessments}

Both the exposure and vulnerability-focused DRAs discussed earlier can be undertaken as separate exercises or integrated into other assessments undertaken during the PPTA.

If the initial analysis suggests that a dedicated assessment is not required, a number of relevant lead questions may be integrated into a range of other PPTA assessments instead. However, the DRA-related aspects still require fully substantiated conclusions and recommendations as relevant. Appendix 3 contains an indicative checklist focusing on exposure (particularly relevant for EIAs and risk assessment management plans [RAMPs]). Appendix 4 provides lead questions focusing on community vulnerability (particularly relevant for social impact and gender assessments). The division between different types of assessment is not cut in stone and individual assessments may consider both sets of questions.

\section{E. Policy- and Results-Based Loans}

Broader sector DRAs may be appropriate in processing policy- and results-based loans focusing on sectors at medium or high disaster risk. These assessments can help identify suitable DRM-related policy reforms and results, for instance pertaining to the introduction of risk-sensitive land-use planning, building code revisions, or the development and implementation of national disaster risk financing strategies (ADB 2017). 


\section{Addressing Disaster Risk across ADB's Key Sectors}

\section{A. Designing and Evaluating Disaster Risk Management Options}

DRAs are intended to inform decisions or recommendations regarding (i) whether existing disaster risks are acceptable (i.e., whether they are within a threshold of predicted losses that is deemed reasonable); (ii) whether the existing or currently planned DRM measures are adequate; and (iii) available opportunities to enhance resilience. If the DRA indicates unacceptable levels of risk in the absence of any DRM actions, the DRA should also provide clear recommendations on appropriate DRM measures, their justification, and an estimation of associated costs.

In theory, DRM measures can address any element of the disaster risk equation - that is, natural hazards, exposure of elements at risk, or their vulnerability. In practice, modifying the hazard is often impossible and the long-term consequences and sustainability of related interventions are not well understood. For instance, there is no known method of preventing volcanic eruptions (although flows of lahars can be controlled) and the understanding of managing the buildup of tectonic strain is still limited (Smith 2001). On the other hand, there are technologies that control landslides, such as drainage or retaining walls. However, these solutions do not work in all landslide hazard contexts, are expensive, and often encounter maintenance issues. Box 4 presents key risk reduction options.

\section{Box 4: Options for Reducing Disaster Risk}

\section{Reducing Hazard}

- Structural measures (drainage, retaining walls, dams, etc.)

\section{Reducing Exposure}

- Risk-sensitive land-use planning

- Relocation of project sites

\section{Reducing Vulnerability/Strengthening Capacity}

- Structural measures (increasing design standards, retrofitting, etc.)

- Nonstructural measures (e.g., diversifying income sources of vulnerable communities, early warning and preparedness, eco-based measures, capacity building, risk awareness education)

Source: ADB.

Exposure can be reduced through risk-sensitive land-use planning to control the type, number, and use of buildings and infrastructure in hazard-prone locations and to direct the concentration of investments to less hazard-prone areas. Actions to reduce vulnerability include both structural and nonstructural measures. Structural measures entail engineering measures, such as retrofitting and construction of hazard-resistant protective structures. Nonstructural measures include early warning systems, eco-based measures (e.g., mangrove planting), income diversification for vulnerable communities, capacity building, disaster risk awareness education, improvements in maintenance practices, and preparedness planning. 
Vulnerability is multifaceted and requires a multidisciplinary approach as actions in multiple sectors (agriculture, education, finance, water, etc.) influence levels of vulnerability.

Certain structural measures such as flood walls or artificial levees have been critiqued for giving communities a false sense of security since there is always a residual disaster risk-for instance, higher flooding levels beyond the height of the flood defenses. Furthermore, the breach of levees or protective walls may increase the intensity of a hazard event, trapping floodwater beyond outflow systems. If designed in isolation, they can also transfer risk to other areas and communities, as for instance is potentially the case for structural river flood defenses.

A careful economic evaluation of all options, both structural and nonstructural, therefore needs to be undertaken before deciding on the most effective and sustainable DRM actions, as highlighted in Box 5. The optimal strategy is often to use a combination of actions. However, optimal strategies will vary between projects and countries, depending on the specific context of each project.

\section{Box 5: Economic Appraisal of Disaster Risk Management Measures}

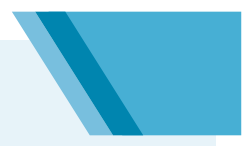

Investment in disaster risk reduction is only warranted from an economic perspective where benefits of investment exceed costs. Disaster risk management (DRM) measures and project design alternatives proposed by a disaster risk assessment should therefore be included in the economic appraisal of a project. Exceptionally, a separate analysis focusing specifically on the DRM measures may be justified-for instance, if they are particularly costly or form a significant stand-alone component of the project.

The economic appraisal of DRM measures requires a solid, well-conceived methodological approach. The approach needs to take into account the fact that benefits result primarily from the avoidance of disaster damage (direct physical damage) and loss (indirect flow consequences), rather than from additional positive flows of income. The expected reduction in losses and implied indirect benefits need to be measured and compared with the cost of proposed risk reduction measures.

The approach and resulting recommendations also need to reflect the fact that the benefits are necessarily probabilistic, only materializing if disasters occur over the life of the investment; that many of the benefits will relate to direct physical and indirect losses that will not ensue should the related hazard occur, rather than to expected streams of positive benefits; and that comprehensive risk assessments may not be available for the project locality. Actual direct and indirect benefits will depend on the number and scale of hazard events occurring over the life of the investment.

Postdisaster needs assessment methodologies provide a useful resource in exploring potential disaster damage and loss. Detailed sector methodologies have been prepared. The UN Development Group, the World Bank, and the European Union have collaborated on the development of a joint Post-Disaster Needs Assessment tool which was published in 2013. These resources are available at:

- http://www.undp.org/content/undp/en/home/librarypage/crisis-prevention-and-recovery/ pdna.html

- http://www.recoveryplatform.org/pdna/

Sources: Benson and Twigg (2007); ADB. 


\section{B. Case Studies of Sector-Specific Disaster Risk Management Measures}

The following case studies illustrate the linkages between DRA and action to reduce risks in five key sectors: agriculture and natural resources, education, energy, transport, and urban infrastructure and services. The case studies highlight projects that have undergone climate and disaster risk assessments and the resulting recommendations to reduce risk. Appendix 5 contains further examples of potential DRM options pertaining to ADB's key sectors.

\section{Agriculture and Natural Resources}

The agriculture sector is particularly vulnerable to extreme weather events such as droughts, floods, tropical cyclones, cold spells, and hail. Climate change could potentially amplify disaster risk by resulting in less predictable weather patterns and more frequent and intense extreme weather events in many areas. Geophysical hazards can also take a toll on agriculture. Landslides, in some cases triggered by geophysical hazards, can reduce the amount of arable land, while earthquakes can destroy irrigation systems, disrupt power transmission, and restrict access to markets. Overall, however, the impact of geophysical hazards on agricultural productivity is relatively less significant than that of extreme weather events. Box 6 provides a range of relevant DRM measures recommended for a water resource management project in rural Afghanistan aimed at increasing agricultural production.

\section{Box 6: Climate Risk Assessment of ADB's Panj-Amu River Basin Project in Afghanistan}

The Panj-Amu River Basin Project in Afghanistan aims at increasing agricultural productivity through improved access to and use of water at the farm, scheme, and river levels. A climate risk assessment conducted for the project identified the possibility of more frequent and intense drought and flooding episodes at the project site in the future. Current flooding already produces erosion in the upstream areas and siltation in the vicinity of irrigation infrastructure. A climatechange-related retreat of the snowline would further increase the instability of upstream slopes, triggering more mudslides and landslides and downstream sedimentation. Droughts currently have a particularly adverse effect on the middle and tail ends of canals due to inefficient irrigation practices (such as the over-irrigation of rice paddies at head ends of the canals). The project has therefore incorporated the following measures to address identified climate and disaster risks:

- climate-proofing of canal headworks to withstand flood events;

- better allocation of water resources through the establishment and training of water user associations and irrigation associations;

- training and demonstrations in the use of more climate-resilient agricultural practices and in improved on-farm water management;

- rain, snow, and river measuring gauges for the improved monitoring of water resources;

- improved water resources planning systems; and

- climate adaptation for watershed management.

Source: ADB (2016b). 


\section{Education}

Schools are critical community assets, often functioning as gathering points or shelters during emergencies as well as places of learning. Their collapse can cause mass casualties and interrupt children's access to education. Inadequate building design, negligent implementation of construction codes, and inadequate maintenance can all contribute to the failure of school buildings. Box 7 highlights a DRA of schools in Armenia.

\section{Box 7: Assessing the Seismic Vulnerability of Schools in Armenia}

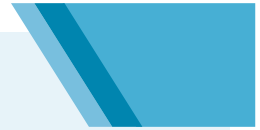

The condition of school buildings in Armenia has caused concerns since the 1988 Spitak earthquake, which buried thousands of children under the debris of school buildings and killed 6,000 students (Balassanian et al. 1995). In 2014-2015, the Asian Development Bank (ADB) assessed the exposure and vulnerability of all 1,440 of the country's schools as part of the processing of the ADB Armenia Seismic Safety Improvement Program. An ADB loan was subsequently approved in 2015 , focusing on the improvement and strengthening of at least 46 schools, as well as support for the development of disaster preparedness plans and earthquake awareness campaigns

The assessment sought to identify those schools most in need of rehabilitation, using a framework developed previously by UNICEF. The assessment looked at existing hazard levels of school locations and used a number of qualitative indicators to identify the level of exposure and vulnerability of each school, including student population, age, building typology, and technical and physical condition. Questionnaires and secondary data were used to inform the assessment. A weighted score was then determined for each school, providing a ranking of schools in terms of rehabilitation and seismic retrofitting needs.

A parallel technical assistance project supported a more in-depth seismic risk assessment of public buildings in four selected cities and validated the results of the initial assessment. This study looked at seismic ground motion parameters and undertook more comprehensive structural assessments of different building types, predicting their behavior under seismic motion conditions, for instance material damage, loss of life, and severe injuries. The assessment identified a number of structural methods for retrofitting as well as conditions under which it would be better to construct a new building.

Source: ADB (2015a; 2015b).

\section{Energy}

The energy sector is highly vulnerable to natural hazards. This vulnerability is not limited to hydropower but extends to nuclear, oil, gas, and coal-based systems, including both power generation facilities as well as transmission and distribution networks (ADB 2012). The inundation of the nuclear power reactors in Fukushima, Japan, in 2011 is a particularly alarming example of the potential impact of a natural hazard, in this case a tsunami and associated flooding triggered by an earthquake which disrupted the coolant systems and caused a nuclear meltdown in three reactors. Geophysical hazards can also cause critical failures in hydropower systems, for instance by destroying higher-altitude dams or water reservoirs with potentially catastrophic consequences for downstream areas. Seismic hazards disrupt transmission and distribution of gas- and oil-supplied energy systems as well, with the risk of collateral fire hazards. Floods and tropical storms have similarly destructive impacts. All types of natural hazard can also potentially damage transmission and distribution networks. 
The indirect impact of energy supply disruptions-electricity supply in particular-affects not only the energy sector but the wider economy, as electricity production is halted or reduced and backup systems such as fuel-fed generators increase production costs. Disaster resilience is therefore linked to both structural and nonstructural factors - that is, to the hazard-proofing of energy sector transmission and distribution systems and to the extent of redundancies to manage disruptions. Managing disruptions also requires the design of emergency measures to contain the impact of collateral hazards caused by the failure of energy infrastructure, such as explosions, fires, and contamination. Box 8 contains an overview of DRM measures taken by a hydropower project in Nepal.

\section{Box 8: Climate Risk Assessment of the Tanahu Hydropower Project in Nepal}

The Tanahu Hydropower Project is a 140-megawatt reservoir-based electricity generation project, located 150 kilometers west of Kathmandu. A climate risk assessment conducted by the Asian Development Bank in 2014 as part of project processing involved a hydrological risk assessment of the Tanahu watershed, including the catchment area upstream from the project site, under different climate change scenarios. The assessment found that flood risks are likely to increase during the rainy season. Risks from other hazards, such as glacial lake outburst floods, landslides, and earthquakes, were considered low to moderate.

The risk assessment found, however, that the design of the project already accommodated the levels of risk identified in particular:

- Dam spillway had been designed to discharge a flow of 47,500 cubic meters per second (against the climate risk assessment estimate of maximum discharge of 8,306 cubic meters per second).

- The project includes flood early warning systems.

- The project will conduct protection works of slopes at high risk from landslides in the upstream area prior to reservoir filling. The risk assessment recommended further monitoring of the slopes during the initial years of operation.

- The seismic design and engineering is considered sufficient.

Source: ADB (2014e).

\section{Transport}

The transport sector, in particular road and rail transport, can suffer damage as a consequence of any type of natural hazard, as witnessed in many countries in Asia and the Pacific. Major events can result in significant damage and large reconstruction bills. While direct damage from more frequent, lower-impact hazard events, such as localized flooding, is comparatively modest, the indirect economic consequences via disruptions in the transport sector can still be significant. Transport disruptions also impede the access of emergency services to disaster-affected areas.

Vulnerability in the transport sector is linked to both structural and nonstructural factors. These include detailed technical and engineering specifications and the broader overall design of a transport system, such as the extent of redundancies in the system in case of network blockages. They also include maintenance policies and procedures, including the timely detection and rehabilitation of weak points in the system. Box 9 illustrates a number of DRM measures taken to reduce the vulnerability of a rural roads improvement project in Cambodia. 


\section{Box 9: Climate Risk Assessment of Cambodia's Rural Roads Improvement Project}

The Rural Roads Improvement Project focuses on rehabilitating the rural road network in seven provinces located mostly around the Tonle Sap basin in Cambodia. Improved rural roads are intended to facilitate access to markets, employment opportunities, and social services for about 560,000 beneficiaries. By paving rural unpaved roads, the project addresses increased dust levels associated with drought, which reduce visibility and create poor local air quality, in turn contributing to respiratory illnesses and subsequent infant mortality. However, the climate risk assessment warned that paving roads could also increase water runoff to surrounding areas during the rainy season. Increasing flood risks and soil moisture during the rainy season were identified as a particular concern. The assessment also included the identification of particularly vulnerable road segments with high levels of environmental degradation and low vegetation cover. In some areas, the erosion of embankments and roads was linked to poorly timed releases of floodwaters from an upstream dam in the past. Coordination with the Ministry of Water was determined currently insufficient to tackle this issue. The resulting project included an output on climate change adaptation, comprising the following activities:

- vulnerability mapping for rural roads to improve planning for climate change;

- introduction of ecosystem-based adaptation strategies focusing on environmental and green planning for project roads to improve flood and drought management (i.e., increasing ground cover and infiltration of water during floods, and water retention during droughts, which have the added benefit of enhancing rural livelihoods by improving the soil structure for agriculture);

- pilot use of climate monitoring systems to improve road management and maintenance, since certain maintenance works can only take place during the dry season but, as seasons are shifting each year, planning is becoming more difficult;

- development of pilot programs for an early warning system and emergency management planning for rural roads; and

- planning of water capture and storage systems, together with the ecosystem measures, to manage the increased intensity of floods and droughts.

Source: ADB (2015a; 2015b).

\section{Urban Infrastructure and Services}

Urban areas are often particularly susceptible to natural hazards due to high levels of exposure in combination with often old and increasingly overstretched infrastructure and services, and large proportions of people living in poverty. In cities, people are often particularly dependent upon critical infrastructure, including transport, electricity, water, sanitation and communications systems, hospitals, and fire, police, and public administration services. Furthermore, urban infrastructure systems are increasingly complex and interdependent, implying cascading consequences of a failure in a particular segment of the system. For instance, almost all types of infrastructure rely on electricity and communication technology. Urban potable water systems, for example, often rely on pressurized pipelines with associated pumps. Failure of electricity makes these systems inoperable and may facilitate leakages of drainage and wastewater into drinking water supplies. As such, the disaster-related destruction of infrastructure can have a magnified impact on densely populated urban areas (GIZ and NIDM 2013).

At the same time, urban areas in many developing countries contain informal settlements in more hazard-prone sections of the city or town that are often undersupplied by critical infrastructure and services. Long-term investment to enhance supply requires consideration of both current exposure and vulnerabilities of these communities to natural hazards and of potential future interdependencies, 
exposure and vulnerabilities to which the installation of physical infrastructure and enhanced provision of services may contribute. Urban DRAs therefore need to adopt a systems-based approach that reflects the integrated but diverse range of stakeholders and sectors and considers the delivery of services as well as infrastructure.

Resilience of urban infrastructure and services is associated with adequate risk-sensitive land-use planning, in particular to limit investments and settlement in highly hazardous areas such as riverbanks and low-lying coastal areas; adequate building codes and their strong enforcement; adequate maintenance of buildings and other infrastructure; critical infrastructure and services network redundancies and backup systems; protective ecosystems; preparedness measures, such as emergency plans and drills; and financial capacity to restore systems following a disaster. Box 10 provides an example of a risk assessment conducted for an ADB urban development project in Bangladesh.

\section{Box 10: Coastal Towns Environmental Infrastructure Project in Bangladesh}

The Coastal Towns Environmental Infrastructure Project aims at increasing climate resilience and disaster preparedness in seven secondary cities in Bangladesh. It provides a multisector range of investments in resilient infrastructure, including drainage and flood control, water supply, sanitation, cyclone shelters, emergency access roads and bridges, slum improvements, bus terminals, boat landings, and markets. Institutional capacity to integrate climate and disaster risks into urban planning is also addressed. The climate risk assessment conducted for the project identified increased frequency and intensity of rainfall-induced flooding and tropical cyclones as the main hazard scenarios and investigated the effects of these hazards on each major component of the project. In consequence, the project includes climate change screening of all infrastructure under the project on the basis of agreed technical selection criteria and consideration of climate projections for 2040 in detailed designs. Sample adaptation measures identified for consideration in detailed design include:

Roads:

- Raise crest level in view of increased rainfall and flooding.

- Undertake additional strengthening of embankments on roads in flood areas.

- Assess need for larger culverts.

Cyclone shelters:

- Raise base level of first floor to avoid higher storm surges.

- Strengthen structures to withstand stronger wind forces.

- Utilize sand sourced from noncoastal areas to avoid saline contamination.

Drainage and flood control:

- Build new and enhance existing drains, taking into account 2040 rainfall projections.

Water supply investments:

- Drill deeper tube wells to explore nonsaline sources.

- Locate surface water intakes based on salinity tests and assessments of sea-level rise.

- Extend vertical upper-well casing of production tube wells to protect against floods and storms.

- Provide power backup to keep water supply system operational during storms.

- Install protection measures (embankment with block pitching) around water treatment plants to protect them from cyclones and storm surges. 
Sanitation investments:

- Construct septic tanks and superstructures of public toilets, school toilets, and community latrines above flood level to avoid inundation during monsoon flooding.

- Position pit of latrines above the flood level.

Nonstructural measures to reduce climate and disaster risk:

- Review and update urban master plans, local building codes, and engineering design standards of the Local Government Engineering Department and Department of Public Health Engineering to incorporate climate change and disaster resilient measures.

- Improve water safety planning and groundwater monitoring through the development of water safety plans and guidelines.

- Establish disaster management standing committees in each town, and deliver appropriate technical training committee members.

Source: ADB (2013a; 2014d). 


\section{Disaster Risk Assessment and ADB's Business Processes}

\section{A. Project Identification and Design}

Figure 5 illustrates how DRAs, CRVAs where relevant (section 2), and their outputs and recommendations can fit into ADB's project management cycle, in particular into the concept, project design, and PPTA process, to strengthen disaster resilience.

Figure 5: Disaster Risk Assessments and ADB Project Cycle

\section{DRA Process}

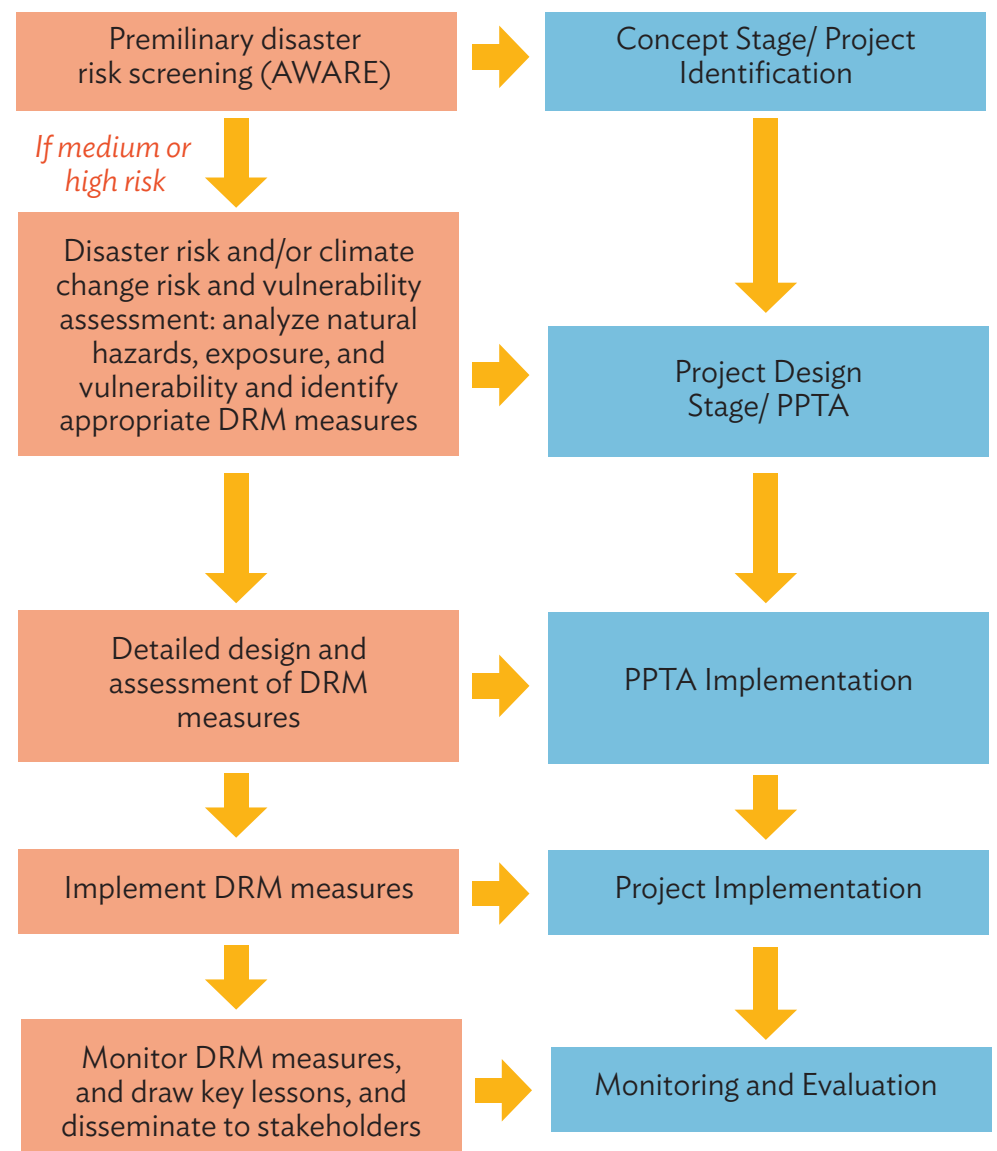

$\mathrm{ADB}=$ Asian Development Bank, DRA = disaster risk assessment, $\mathrm{DRM}=$ disaster risk management, $\mathrm{PPTA}=$ project preparatory technical assistance.

Source: Adapted from ADB (2013). 
Section 2 of this document discusses the steps and available instruments to perform a checklist-based prescreening and preliminary screening of disaster risk during project identification. ${ }^{10}$ Sections 2 and 4 provide further detailed guidance in determining the DRA and/or CRVA requirements and types of DRA during project design if the preliminary screening process indicates medium or high disaster risk. If a DRA or CRVA is required, it may demonstrate that the proposed project design is already sufficiently disaster resilient and not suggest further action. Only if the project is found to have significant vulnerabilities should the DRA proceed to develop DRM options. These options then need to be evaluated in terms of their technical feasibility and cost efficiency and, if approved, implemented. This often requires the participation of further stakeholders and additional technical capacity-building activities.

DRAs and CRVAs are situated somewhere between the project design and PPTA implementation phase. This means that less comprehensive assessments can be integrated into the project/PPTA design phase, while in-depth assessments (including the elaboration of options to reduce disaster risks) should continue into PPTA implementation. Key findings from DRAs should be integrated into the overall assessment of the project (including the stakeholder and problem analysis) and DRM measures identified to enhance resilience, as relevant.

\section{B. Monitoring Disaster Risk and Disaster Risk Management}

The design and monitoring framework (DMF) is a key component of project documentation and captures critical information about a project in four columns. Figure 6 provides a snapshot overview of possible entry points for results from a DRA and for the monitoring of DRM measures.

Figure 6: Disaster Risk Management and ADB's Design and Monitoring Framework

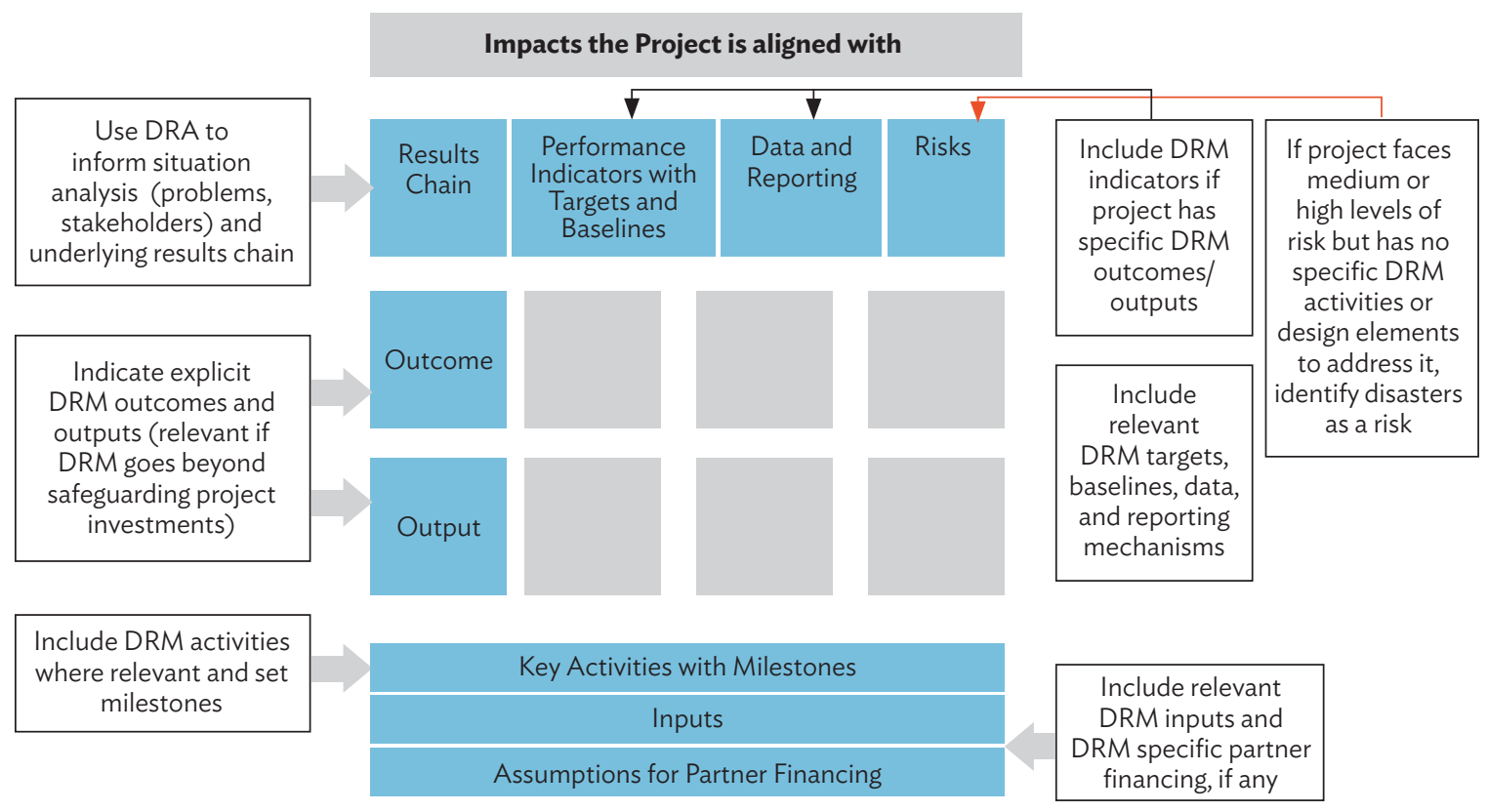

DRA = disaster risk assessment, $\mathrm{DRM}=$ disaster risk management

Source: Adapted from ADB (2016a).

${ }^{10}$ In some cases, disaster risk should also be screened as an element in preparing any required resettlement plan because (i) resettlement bears the risk of relocating people to a more hazardous environment; and (ii) conversely, sometimes resettlement can reduce disaster risk. 
The degree of prominence given to disaster risk and DRM measures in a DMF and other project documents will depend on their importance to a project's outcomes. DRM-related performance indicators are required if a project has an explicit DRM subcomponent or the project outcome directly relates to enhanced DRM. A few examples of possible DRM indicators are included in Appendix 6. Baselines established through the DRA can be used to monitor these indicators and to help identify data sources for monitoring purposes.

If a project faces high levels of risk but does not include specific DRM components, disaster risk should be included in the section on risks/assumptions in the DMF and the associated RAMP. Relevant key activities could also be included in the project's environmental management plan (EMP). EMPs or RAMPs lack indicators, and the extent of monitoring activities and periodicity will depend on the project's specific risks and impacts (ADB 2009).

The monitoring of DRM-related project activities, including in the RAMP and EMP, should be integrated into ADB's project performance management system through the following activities:

- Conduct site visits for high-risk projects.

- Conduct supervision missions with detailed reviews of the implementation of DRM measures by ADB technical staff and safeguard specialists/expert consultants, as relevant.

- Review periodic monitoring reports submitted by borrowers/clients for agreed DRM works or activities.

- Prepare a project completion report that assesses whether possible DRM-related activities, including in the EMP or RAMP, have been effective based on the initial baseline and monitoring findings. 


\section{Glossary}

Climate change adaptation. In human systems, the process of adjustment to actual or expected climate and its effects in order to moderate harm or exploit beneficial opportunities. In natural systems, the process of adjustment to actual climate and its effects; human intervention may facilitate adjustment to expected climate (IPCC 2012).

Digital elevation model. A digital file consisting of terrain elevations for ground positions at regularlyspaced horizontal intervals (USGS 2017).

Disaster. A serious disruption of the functioning of a community or a society at any scale due to hazardous events interacting with conditions of exposure, vulnerability, and capacity, leading to one or more of the following: human, material, economic, and environmental losses and impacts (UNISDR 2017).

Disaster risk. The potential loss of life, injury, or destroyed or damaged assets which could occur to a system, society or a community in a specific period of time, determined probabilistically as a function of hazard, exposure, vulnerability, and capacity (UNISDR 2017).

Disaster risk assessment. A qualitative or quantitative approach to determine the nature and extent of disaster risk by analyzing potential hazards and evaluating existing conditions of exposure and vulnerability that together could harm people, property, services, livelihoods, and the environment on which they depend (UNISDR 2017).

Disaster risk management. The application of disaster risk reduction policies and strategies to prevent new disaster risk, reduce existing disaster risk, and manage residual risk, contributing to the strengthening of resilience and reduction of disaster losses (UNISDR 2017).

Disaster risk reduction. Denotes both a policy goal or objective and the strategic and instrumental measures employed for anticipating future disaster risk; reducing existing exposure, hazard, or vulnerability and improving resilience (IPCC 2012).

Embedded disaster risk reduction. Measures integrated into project design to enhance their disaster resilience but which are not reflected in the explicit intended impact or outcome of the project.

Exposure. The presence of people, livelihoods, environmental services and resources, infrastructure, or economic, social, or cultural assets in places that could be adversely affected (IPCC 2012).

Global positioning system. A space-based radionavigation system owned by the United States that helps pinpoint a three-dimensional position to about 1 meter of accuracy (for example latitude, longitude, and altitude) and provide nano-second precise time anywhere on earth (NASA 2015).

Hazard. A process, phenomenon, or human activity that may cause loss of life, injury, or other health impacts, property damage, social and economic disruption, or environmental degradation. (UNISDR 2017). 
Land-use planning. The process undertaken by public authorities to identify, evaluate, and decide on different options for the use of land, including consideration of long-term economic, social, and environmental objectives and the implications for different communities and interest groups, and the subsequent formulation and promulgation of plans that describe the permitted or acceptable uses (UNISDR 2009).

Residual risk. The disaster risk that remains in unmanaged form, even when effective disaster risk reduction measures are in place, and for which emergency response and recovery capacities must be maintained (UNISDR 2009).

Resilience. The ability of a system, community, or society exposed to hazards to resist, absorb, accommodate, adapt to, transform, and recover from the effects of a hazard in a timely and efficient manner, including through the preservation and restoration of its essential basic structures and functions through risk management (UNISDR 2017).

Satellite imagery. A picture of the earth from space. These images are generated using sensors that perceive the various light or temperature wavelengths to create an image of clouds, water vapor, or land (NOAA 2013).

Stand-alone disaster risk reduction projects. Projects with disaster risk reduction as their primary objective (e.g., a flood risk management project).

Topographic map. Detailed, accurate graphic representation of features that appear on the earth's surface. These features include cultural features (roads, buildings, urban development, railways, airports, names of places and geographic features, administrative boundaries, state and international borders, reserves); hydrography features (lakes, rivers, streams, swamps, coastal flats); relief features (mountains, valleys, contours and cliffs, depressions); and vegetation features (wooded and cleared areas, vineyards, and orchards). A map legend (or key) lists the features shown on that map, and their corresponding symbols. Topographic maps usually show a geographic graticule and a coordinate grid, so you can determine relative and absolute positions of mapped features (Geoscience Australia 2017).

Vulnerability. The conditions determined by physical, social, economic, and environmental factors or processes which increase the susceptibility of an individual, a community, assets, or systems to the impacts of hazards (UNISDR 2017). 


\section{References}

ADB. 2004. Disaster Emergency Assistance Policy. Manila.

- - 2008. Strategy 2020: The Long-Term Development Framework of the Asian Development Bank, 2008-2020. Manila.

- - 2009. Safeguard Policy Statement. Manila.

- - 2010. Report and Recommendation of the President to the Board of Directors: Proposed Loan for the Kingdom of Cambodia for the Rural Roads Improvement. Manila.

- - . 2012. Climate Risk and Adaptation in the Electric Power Sector. Manila.

- - . 2013. Guidelines for Climate-Proofing Investments in the Energy Sector. Manila.

-_- 2014a. Operational Plan for Integrated Disaster Risk Management, 2014-2020. Manila.

- - . 2014b. Climate Risk Management in ADB Projects. Brochure.Manila.

- - . 2014c. Aware for Projects User Guide. V1.5. Manila.

- - . 2014d. Report and Recommendation of the President to the Board of Directors: Proposed Loan and Administration of Loan and Grants to the People's Republic of Bangladesh for the Coastal Towns Environmental Infrastructure Project. Manila.

-_- 2014e. Technical Assistance: Preparing Hydropower Development for Energy Crisis in Nepal. Consultant's report. Manila.

- - - 2015a. Report and Recommendation of the President to the Board of Directors: Proposed ResultsBased Loan and Technical Assistance Grant to Armenia for the Seismic Safety Improvement Program. Manila. - - - 2015b. Seismic Risk Study of Public Building in the Cities of Dilijan, Gyumri, Jermuk and Vanadzor. Consultant's Report. Manila.

_-_. 2016a. Guidelines for Preparing a Design and Monitoring Framework. Manila.

- - . 2016b. Report and Recommendation of the President to the Board of Directors: Proposed Grant and Administration of Grant to the Islamic Republic of Afghanistan for the Panj-Amu River Basin Sector Project. Manila.

- - - 2017. Disaster Risk Management and Country Partnership Strategies: A Practical Guide. Manila.

Australian Geomechanics Society. 2000. Landslide Risk Management Concept and Guidelines. Australian Geomechanics. Vol. 35 No. 1.

Balassanian, S.Y., A.R. Arakelian, S.N. Nazaretian, A.S. Avanessian, A.H. Martirossian, V.A. Igournnov, M.G. Melkoumian, A.V. Manoukian, and A.K. Tovmassian. 1995. Retrospective Analysis of the Spitak Earthquake. Annali Geofizika. Vol. XXXVIII, N, 3-4, September-October.

Benson, C., and J. Twigg. 2007. Tools for Mainstreaming Disaster Risk Reduction. Guidance Notes for Development Organizations. Geneva: ProVention Consortium.

GIZ and National Institute of Disaster Management (NIDM). 2013. Training Module: Critical Infrastructures and Disaster Risk Reduction. New Delhi. 
Government of Australia, Geoscience Australia. What Is a Topographic Map? http://www.ga.gov.au/ scientific-topics/national-location-information/topographic-maps-data/basics/what-is-a-topographicmap, accessed 10 June 2017)

Intergovernmental Panel on Climate Change (IPCC). 2012. Managing the Risks of Extreme Events and Disasters to Advance Climate Change Adaptation. Special Report on Managing the Risks of Extreme Events and Disasters to Advance Climate Change Adaptation (SREX). http://ipcc-wg2.gov/SREX/report/fullreport/

Lang, K. 2002. Seismic Vulnerability of Existing Buildings. Institute of Structural Engineering, ETH Zurich, Report No. 273. Zurich: Institute of Structural Engineering, Swiss Federal Institute of Technology.

National Aeronautics and Space Administration (NASA). 2015. Global Positioning System. https://www. nasa.gov/directorates/heo/scan/communications/policy/GPS.html (last updated 31 July 2015, accessed 15 June 2017).

National Oceanic and Atmospheric Administration (NOAA), Office of Satellite and Product Operations. Imagery. http://www.ospo.noaa.gov/Organization/FAQ/imagery.html (last updated 24 May 2013, accessed 15 June 2017).

Neumann, B., A.T. Vafeidis, J. Zimmermann, and R.J. Nicholls. 2015. Future Coastal Population Growth and Exposure to Sea-Level Rise and Coastal Flooding - A Global Assessment. PLoS ONE 10(3): e0118571. doi:10.1371/journal.pone.0118571

Smith, K. 2001. Environmental Hazards: Assessing Risk and Reducing Disaster. 3rd ed. London: Routledge.

United Nations Office for Disaster Risk Management (UNISDR). 2009.Terminology on Disaster Risk Reduction. http://www.unisdr.org/we/inform/publications/7817

- - - 2017. Terminology. https://www.unisdr.org/we/inform/terminology (accessed 12 March 2017).

United States Geological Survey (USGS). Landslides Glossary. https://landslides.usgs.gov/learn/glossary. php\#d (accessed 15 June 2017). 


\section{Further Reading}

\section{ADB Policy and Strategy Documents}

ADB. 2004. Disaster Emergency Assistance Policy. Manila.

- - 2008. Strategy 2020: The Long-Term Development Framework of the Asian Development Bank, 2008-2020. Manila.

_-_. 2009. Safeguard Policy Statement. Manila.

_- - 2010. Addressing Climate Change in Asia and the Pacific: Priorities for Action. Manila.

\section{ADB Operational Guidelines, Procedures and Memoranda}

ADB. n.d. Rapid Environmental Assessment Checklist (REA). Template. Manila.

_-_ . n.d. Checklist for Preliminary Climate Risk Screening. Template. Manila.

_-_ . 2010. Memorandum on Streamlined Business Processes. Manila.

_-_. 2010. Processing Sovereign and Sovereign-Guaranteed Loan Proposals. Operations Manual. OM D11/BP. Manila.

_-_. 2012. Environment Safeguards. A Good Practices Sourcebook. Manila.

-_- 2012. Handbook on Poverty and Social Analysis. Manila.

_-_. 2014. Aware for Projects User Guide. V1.5. Manila.

-- . 2014. Climate Risk Management in ADB Projects. Brochure. Manila.

- - . 2014. Operational Plan for Integrated Disaster Risk Management, 2014-2020. Manila.

-_- 2016. Guidelines for Preparing a Design and Monitoring Framework. Manila.

-_- 2017. Climate Change Strategic Framework 2017-2030: Enhanced Actions for Low Greenhouse Gas Emissions and Climate-Resilient Development. Manila.

- - 2017. Disaster Risk Management and Country Partnership Strategies: A Practical Guide. Manila.

-_- 2017. Natural Hazard Data: A Practical Guide. Manila.

\section{ADB Project Disaster and Climate Risk Assessment Documents}

ADB. 2010. Report and Recommendation of the President to the Board of Directors: Proposed Loan for the Kingdom of Cambodia for the Rural Roads Improvement. Manila.

_- - 2013. Technical Assistance for Preparing Coastal Town's Infrastructure Project. Volume 3. Climate Change Assessment and Adaptation Strategy. Consultant's report. Manila.

- - - 2014. Report and Recommendation of the President to the Board of Directors: Proposed Loan and Administration of Loan and Grants to the People's Republic of Bangladesh for the Coastal Towns Environmental Infrastructure Project. Manila.

- - 2 2014. Scoping Tools and Guidance Materials Promoting the Mainstreaming of Climate and Disaster Risk into ADB's Key Business Processes. Consultant's report. Manila. 
_-_. 2014. Technical Assistance for Preparing Hydropower Development for Energy Crisis in Nepal. Consultant's report. Manila.

- - 2015. Report and Recommendation of the President to the Board of Directors: Proposed Results-Based Loan and Technical Assistance Grant to Armenia for the Seismic Safety Improvement Program. Manila.

-_- 2015. Seismic Risk Study of Public Building in the Cities of Dilijan, Gyumri, Jermuk and Vanadzor. Consultant's report. Manila.

-_- 2015. Strengthening City Disaster Risk Financing in Viet Nam. Manila.

- - 2016. Report and Recommendation of the President to the Board of Directors: Proposed Grant and Administration of Grant to the Islamic Republic of Afghanistan for the Panj-Amu River Basin Sector Project. Manila.

Intergovernmental Panel on Climate Change (IPCC). 2013. Climate Change 2013: The Physical Science Basis. Contribution of Working Group I to the Fifth Assessment Report of the Intergovernmental Panel on Climate Change. T.F. Stocke et al (eds.). United Kingdom and New York, United States: Cambridge University Press, Cambridge.

\section{Literature on Disaster Risk Assessments and Disaster Risk Management Indicators}

Australian Geomechanics Society. 2000. Landslide Risk Management Concept and Guidelines. Australian Geomechanics. Vol. 35 No. 1.

Balassanian, S.Y., A.R. Arakelian, S.N. Nazaretian, A.S. Avanessian, A.H. Martirossian, V.A. Igournnov, M.G. Melkoumian, A.V. Manoukian, and A.K. Tovmassian. 1995. Retrospective Analysis of the Spitak Earthquake. Annali Geofizika. Vol. XXXVIII, N, 3-4, September-October.

Bollin, C., and R. Hidajat. 2006. Community-Based Disaster Risk Index: Pilot Implementation in Indonesia. In: J. Birkmann (ed.) Measuring Vulnerability to Natural Hazards: Towards Disaster Resilient Societies. Tokyo and New York: United Nations University Press.

Chakhraborty, A., and P.K. Joshi. 2016. Mapping Disaster Vulnerability in India Using Analytical Hierarchy Process. Geomatics, Natural Hazards and Risk 7(1): 308-325.

Climate and Development Knowledge Network (CDKN). 2014. Risk Informed Decision Making: An Agenda for Improving Risk Assessments under HFA 2. London.

Eychaner, J.H. 2015. Lessons from a 500-Year Record of Flood Elevations. Association of State Floodplain Managers, Technical Report 7. Madison, WI: Association of State Floodplain Managers.

Global Facility for Disaster Reduction and Recovery (GFDRR). 2014. Understanding Risk: The Evolution of Disaster Risk Assessment. Washington, DC.

Hahn, H., J.C. Villagrán De León and R.Hidajat. 2003. Indicators and Other Disaster Risk Management Instruments for Communities and Local Governments. Washington, DC: Inter-American Development Bank.

Inter-American Development Bank (IDB). 2011. Indicators for Risk and Disaster Risk Management: Programme for Latin America and the Caribbean. Washington, DC.

Intergovernmental Panel on Climate Change (IPCC). 2012. Managing the Risks of Extreme Events and Disasters to Advance Climate Change Adaptation. Special Report on Managing the Risks of Extreme Events and Disasters to Advance Climate Change Adaptation (SREX). http://ipcc-wg2.gov/SREX/report/fullreport/

Lang, K. 2002. Seismic Vulnerability of Existing Buildings. Institute of Structural Engineering, ETH Zurich, Report No. 273. Zurich: Institute of Structural Engineering, Swiss Federal Institute of Technology. 
Neumann, B., A.T. Vafeidis, J. Zimmermann, and R.J. Nicholls. 2015. Future Coastal Population Growth and Exposure to Sea-Level Rise and Coastal Flooding - A Global Assessment. PLoS ONE 10(3): e0118571. doi:10.1371/journal.pone.0118571

Smith, K. 2001. Environmental Hazards: Assessing Risk and Reducing Disaster. 3rd ed. London: Routledge.

United Nations Office for Disaster Risk Management (UNISDR). 2015. Making Development Sustainable: The Future of Disaster Risk Management. Global Assessment Report on Disaster Risk Reduction. Geneva.

van Westen, C.J., D. Alkema, M.C.J. Damen, N. Kerle, and N.C. Kingma. 2011. Multi-Hazard Risk Assessment. Disaster Education Course. Guide Book. United Nations University \& ITC School on GeoInformation Management.

World Bank. 2005. Natural Disaster Hotspots: A Global Risk Analysis. Washington, DC.

\section{Literature on Disaster Risk Management and Climate Change Adaptation Mainstreaming and Resilience}

ADB. 2013. Investing in Resilience. Ensuring a Disaster-Resistant Future. Manila.

-_- 2014. Urban Climate Change Resilience: A Synopsis. Manila.

Benson, C., and J. Twigg. 2007. Tools for Mainstreaming Disaster Risk Reduction. Guidance Notes for Development Organizations. Geneva: ProVention Consortium.

New Partnership for Africa's Development (NEPAD). 2004. Guidelines for Mainstreaming Disaster Risk Assessment in Development. Johannesburg.

Turnbull, M., C.L. Sterrett, and A. Hilleboe. 2013. Toward Resilience. A Guide to Disaster Risk Reduction and Climate Change Adaptation. Rugby, UK: Practical Action Publishing.

\section{Literature on Sector-Specific Disaster Risk Management and Climate Change Mainstreaming}

ADB. 2011. Guidelines for Climate Proofing Investment in the Transport Sector: Road Infrastructure Projects. Manila.

- - 2012. Climate Risk and Adaptation in the Electric Power Sector. Manila.

-_- . 2012. Guidelines for Climate Proofing Investment in Agriculture, Rural Development, and Food Security. Manila.

- - 2013. Flood Risk Management: A Strategic Approach. Manila.

_-_. 2013. Guidelines for Climate-Proofing Investments in the Energy Sector. Manila.

Asian Disaster Preparedness Center (ADPC). 2013. Integrating Disaster Risk Management into Urban Management. Disaster Risk Management Practitioner's Handbook Series. Bangkok.

Food and Agriculture Organization of the United Nations (FAO). 2013. Mainstreaming Disaster Risk Reduction into Agriculture: A Case Study from Bicol Region, Philippines. Rome.

FAO. 2014. Mainstreaming Disaster Risk Reduction in Agriculture: An Assessment of progress made against the Hyogo Framework of Action. Input Paper for GAR 2015.

GIZ and National Institute of Disaster Management (NIDM). 2013. Training Module: Critical Infrastructures and Disaster Risk Reduction. New Delhi.

United Nations Environment Programme (UNEP). 2015 Promoting Ecosystems for Disaster Risk Reduction and Climate Risk Management. Opportunities for Integration. 
World Bank. 2012. Resilient Infrastructure for Sustainable Services. Latin America: Mainstreaming of Disaster Risk Management in the Water Supply and Sanitation Sector. Washington, DC.

\section{General}

Institute of Development Studies (IDS). 2010. Assessing Progress on Integrating Disaster Risk Reduction and Climate Change Adaptation into Development Processes. Strengthening Climate Resilience Discussion Paper No. 2. Sussex.

United Nations Office for Disaster Risk Management (UNISDR). 2009.Terminology on Disaster Risk Reduction. http://www.unisdr.org/we/inform/publications/7817

- - 2017. Terminology. https://www.unisdr.org/we/inform/terminology

World Bank and the United Nations. 2010. Natural Hazards, Unnatural Disasters: The Economics of Effective Prevention. Washington, DC, and New York. 


\section{Appendix 1: Disaster Risk Assessment: Step-by-Step Guide}

Disaster risk is a function of hazard, exposure, and vulnerability (section 3 of main document). The hazard component refers to the probability of occurrence of a hazard event of varying intensity for a defined geographical area. Exposure quantifies the assets or elements in that area and their replacement value. Vulnerability captures the degree of damage to specific assets or types of asset as a consequence of a hazard event of varying intensity. Disaster risk assessment (DRA) pulls the three components together, determining the relationship between hazard, exposure, and vulnerability. DRA can be undertaken using quantitative or qualitative methodologies and the implied disaster risk.

This appendix provides more detailed guidance on the assessment and measurement of each of the three components of disaster risk and their integration into a disaster risk assessment. Further guidance on spatial data requirements, key sources and computer applications for natural hazard, exposure, vulnerability, and loss data are provided in Appendix 2.

\section{STEP 1: NATURAL HAZARD ASSESSMENT}

A hazard is a "process, phenomenon or human activity that may cause loss of life, injury or other health impacts, property damage, social and economic disruption or environmental degradation" (UNISDR 2017).

Figure A1.1: Natural Hazard Assessment

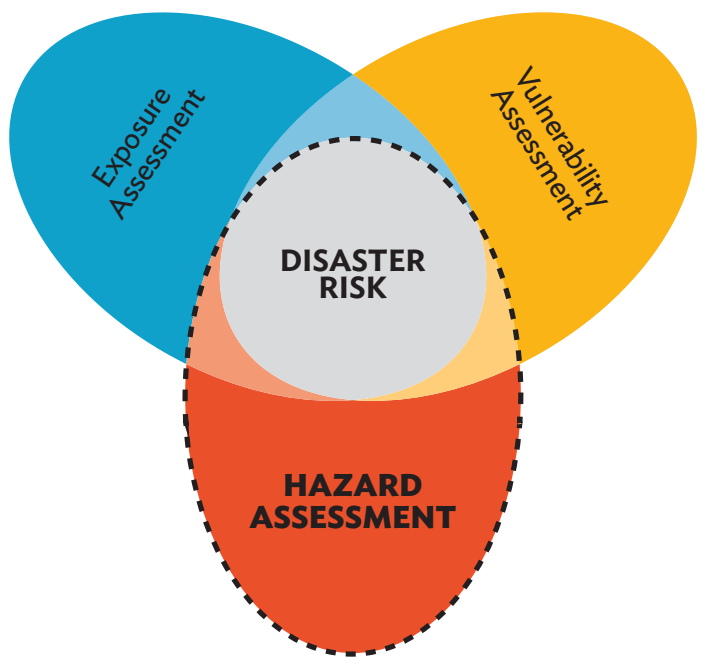

Source: ADB. 
Natural hazard assessment is the first step in the risk assessment process (Figure A1.1). It strives to answer the following key questions:

- What type(s) of natural hazard can happen?

- Where will they happen?

- What is their strength?

- How often will they occur?

In order to answer these questions, hazard analysis focuses on three main characteristics: intensity, frequency, and size or location of the natural hazard.

- Intensity is the observed or potential strength of a given natural hazard, for example the wind speed of a tropical cyclone or the magnitude of an earthquake.

- Frequency relates to how often a natural hazard of a particular intensity is likely to occur, or has occurred, in a given location. This probability is often expressed in return periods.

- Location refers to the affected geographical area. Natural hazards are inherently spatial phenomena. Natural hazards and their characteristics are therefore most often communicated as maps.

\subsection{Measuring the Intensity of a Natural Hazard}

The hazard assessment determines the potential scale of intensity of each type of natural hazard in the geographical area of interest. 'The following section refers to three key natural hazards only. For a full overview and more in-depth discussion of natural hazards, please refer to the companion practical guide on natural hazard assessment.

\section{Earthquakes}

Scientists use a variety of measures to describe the relative size of earthquakes. This includes magnitude, which is the amount of energy released as the result of seismic activity at the source, and intensity, which is the site-specific amount of shaking experienced across the affected area. ${ }^{2}$ For purposes of hazard assessment, earthquake is frequently described in terms of peak ground acceleration. Ground acceleration, in seismological terms, is the increase in speed of motion ${ }^{3}$ of the earth during a seismic event. Peak ground acceleration for hazard modeling is, therefore, the maximum predicted acceleration at a specific site for a given event or return period.

\section{Tropical Cyclones}

Tropical cyclones typically present three kinds of natural hazard, each of which can be modeled separately: wind, rainfall, and coastal storm surge. Storm surges are often the deadliest, although precipitation can cause inland flooding or induce landslides with severe impacts. Storm surge is usually measured as runup distance; wind as wind speed, often the maximum speed sustained for a period of 3 seconds or more; and precipitation as millimeters of rainfall or depth of inundation. Tropical cyclones are monitored and classified by different national and international agencies around the world, depending on the region in which they occur. Most scales rely on wind speed, either maximum or sustained gust, to categorize the severity of a cyclone.

\footnotetext{
The following hazard descriptions are an extract from the companion practical guide on natural hazard assessment.

Detailed information about the measurement of seismic activity can be found at http://www.usgs.gov/faq/taxonomy/term/9828.

See http://earthquake.usgs.gov/learn/glossary/?term=acceleration.
}
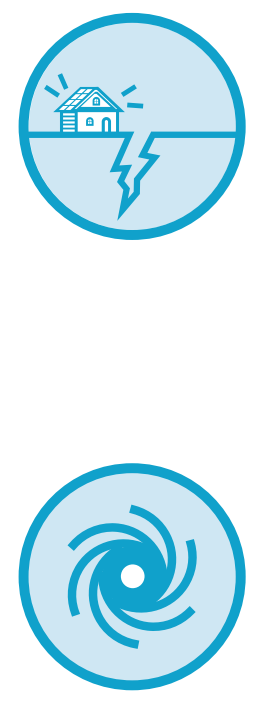


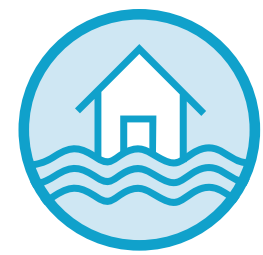

\section{Flood (Riverine)}

Riverine floods typically occur in downstream low-lying floodplains and are triggered by intense rainfall events or seasonal snowmelt. Flood modeling seeks to produce understanding about the potential behavior and intensity of flood events under various rainfall conditions. Natural hazard is most often represented by depth, extent, and, in some cases, rate of flow of a river for a given rainfall event or return period. Flood modeling is an extremely data-intensive process that requires both detailed projections of future rainfall (Box A1.1) and high-resolution baseline data characterizing the key hydrological features of the study area for local planning purposes. As a result, most detailed flood hazard assessments tend to be for localized areas, while national-scale flood hazard information is relatively coarse in resolution.

\section{Box A1.1: Future Changes in the Frequency and Intensity of Extreme Weather Events}

Climate change is expected to impact extreme weather events in complex and significant ways. Although the unequivocal causal link between climate change and change in patterns of extreme weather events is yet to be established, there is a meaningful consensus that the increased energy in the global climate system caused by enhanced greenhouse gas effects will have an impact on weather variability. Recent studies show that a changing climate would have the most severe impact on water resources. As climate change disrupts the hydrologic cycle, water evaporation from the oceans leads to unprecedented rainfall and more severe storms; more extreme coastal, fluvial (or riverine), and pluvial floods; and deeper and longer droughts. Water flows in watersheds, as well as the quality of aquatic and marine ecosystems, are affected.

According to the Fifth Assessment Report of the Intergovernmental Panel on Climate Change (IPPC 2013), Asia is anticipated to experience more frequent and intense heat waves and an increase in heavy rain events, both during monsoons and near the center of tropical cyclones making landfall, along with widespread issues related to water shortage. The IPCC expects that major effects of climate change on Pacific island countries will include sea-level rise, increased intensity and frequency of tropical cyclones, and more frequent extreme rainfall events.

The effects of climate change on extreme weather events will be geographically specific. At present, the global climate models cannot be downscaled to the degree that would make high-resolution assessment of this relationship possible. However, many useful qualitative estimates have been conducted and the models are improving. Any efforts to create or understand information about extreme weather events must therefore consider the projected impacts of climate change, and in particular the increased variability in weather patterns, in the geographic area under consideration.

Generally speaking, the coastal areas of a number of developing countries are particularly prone to storms and storm surges, coastal flooding, and salinity intrusion of increasing frequency and magnitude. Several coastal cities and communities are already suffering the consequences.

Source: ADB (2017a; 2017b)

\subsection{Analyzing Return Periods}

The return period is one of the most important results when analyzing natural hazard information. It describes the probability that an event (a particular type of natural hazard of specified intensity in a given location) may happen in the future. While the likelihood that areas exposed to natural hazards, such as a city on a major fault line, will experience a hazard is $100 \%$, this information is only of limited utility unless the hazard probability is described in relation to a specific period of time and level of intensity. So-called 
"return periods" express the probability of a natural hazard event of a specific intensity occurring, for instance, describing a 6.5-magnitude earthquake as a 100- or 200-year event. However, return periods are merely averages. Actual intervals between two 100-year floods, say, may be much shorter or longer. For instance, on the Danube River at Passau, Germany, the actual intervals between 100-year floods over an observation period of 500 years ranged between 37 and 192 years (Eychaner 2015). It can therefore be more meaningful to translate return periods into the annual probability of a hazard. For example, a 100 -year flood is a flood of an intensity that has a $1 \%$ probability of occurring (i.e., of flooding reaching or exceeding the associated flooding levels) in any given year, as indicated in Table A1.1.

Table A1.1: Return Period and Annual Probability

\begin{tabular}{|cc|}
\hline Event/Years & Annual Probability \\
\hline 1 in 100 & $1 \%$ \\
\hline 1 in 50 & $2 \%$ \\
\hline 1 in 20 & $5 \%$ \\
\hline 1 in 10 & $10 \%$ \\
\hline 1 in 5 & $20 \%$ \\
\hline 1 in 2 & $50 \%$ \\
\hline
\end{tabular}

Source: ADB.

There is an inverse relationship between the frequency and intensity of a natural hazard-that is, more severe occurrences of a particular type of natural hazard in a given location will occur less frequently than less severe ones. However, determining the actual relationship between hazard frequency and intensity in a given location requires fairly complete, long-term historical records or robust hazard models. The latter are particularly important to estimate the intensity of more extreme events with very low return periods, which may not be covered by historical records. If historical records are highly limited and modeled hazard data unavailable, a more qualitative assessment that assigns descriptive levels of likelihood to different hazard intensity scenarios may be considered. Assignment of these descriptors may be based on expert consultations, field investigations, and/or community-based assessments.

\subsection{Natural Hazard Mapping}

The objective of a natural hazard assessment is to identify which areas are prone to natural hazards and to what level of intensity. This is a function of certain topographical, geological, hydrometeorological, and climate characteristics. For instance, landslides require a minimum slope gradient. However, not all steep slopes harbor landslides. Other conditions and factors also need to be taken into account, such as precipitation, seismicity, vegetation cover, and land use. Hazard maps represent the results of this location-specific analysis. They can be produced for single or multiple natural hazards depending upon the hazard context and the intended use of the map. A flood hazard map is presented in Figure A1.2. Further information on spatial data is provided in Appendix 2. 


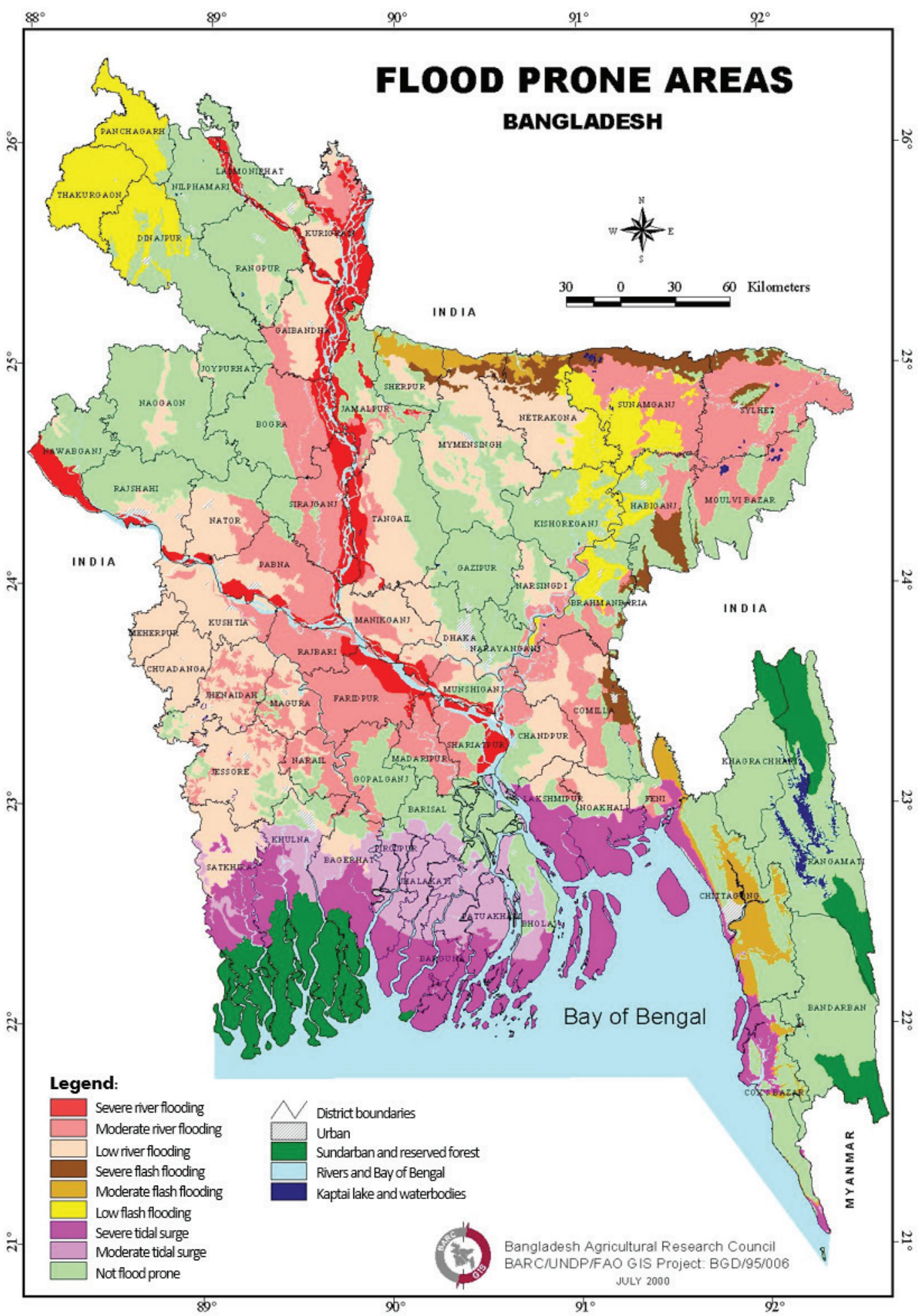

Source: Bangladesh Agricultural Research Council. 2000. BARC/UNDP/FAO FIS Project: BGD/95/006. 
The required level of detail of the analysis also needs to be determined. A larger scale or higher-resolution analysis provides greater detail, but such detail is only necessary for certain applications. Users should consider for what purpose data will be used and what decisions will be made based on that information. For regional scale planning or for identifying first-order priorities, 100 - or 500-kilometer resolution data may be sufficient. For planning related to very local landslides or to flood risk management interventions, even 30-meter resolution data may need to be supplemented with detailed site surveys. Table A1.2 summarizes relevant scales of natural hazard maps for different purposes.

\section{Table A1.2: Required Natural Hazard Map Scales According to Intended Application}

\begin{tabular}{|c|c|c|}
\hline Scale & Coverage & Application(s) (indicative) \\
\hline $\begin{array}{l}\text { Highly localized: } \\
\text { 1:200-1:2,000 } \\
\text { (possibly to be } \\
\text { supplemented by more } \\
\text { detailed images) }\end{array}$ & - Project or construction sites & $\begin{array}{l}\text { - Detailed engineering design of } \\
\text { infrastructure }\end{array}$ \\
\hline $\begin{array}{l}\text { Local: } \\
\text { 1:2,000-1:25,000 }\end{array}$ & $\begin{array}{l}\text { - Human settlements/parts of } \\
\text { a city or municipality }\end{array}$ & $\begin{array}{l}\text { - Preliminary engineering or project } \\
\text { design } \\
\text { - Contingency or disaster preparedness } \\
\text { plans } \\
\text { - Basis for quantitative risk assessments }\end{array}$ \\
\hline $\begin{array}{l}\text { Medium: } \\
\text { 1:25,000-1:100,000 }\end{array}$ & $\begin{array}{l}\text { - Whole municipalities or } \\
\text { small catchments }\end{array}$ & $\begin{array}{l}\text { - Urban planning } \\
\text { - Urban transport/energy/ water project }\end{array}$ \\
\hline $\begin{array}{l}\text { Regional: } \\
\text { 1:100,000-1:500,000 }\end{array}$ & $\begin{array}{l}\text { - Large catchment areas } \\
\text { - Regions, provinces, or large } \\
\text { districts }\end{array}$ & $\begin{array}{l}\text { Design of larger, geographically spread } \\
\text { infrastructure projects (e.g., rural } \\
\text { roads, irrigation) }\end{array}$ \\
\hline
\end{tabular}

Source: Adapted from van Westen et al. (2011).

Some DRAs may require several natural hazard maps at different scales in order to inform the design of individual project subcomponents (e.g., a bridge, power substation, or a small drainage system) and the overall project. 


\section{STEP 2: IDENTIFYING EXPOSED ASSETS}

Exposure concerns "the presence of people, livelihoods, environmental services and resources, infrastructure or economic, social, or cultural assets in places that could be adversely affected" (IPCC 2012).

Figure A1.3: Exposure Assessment

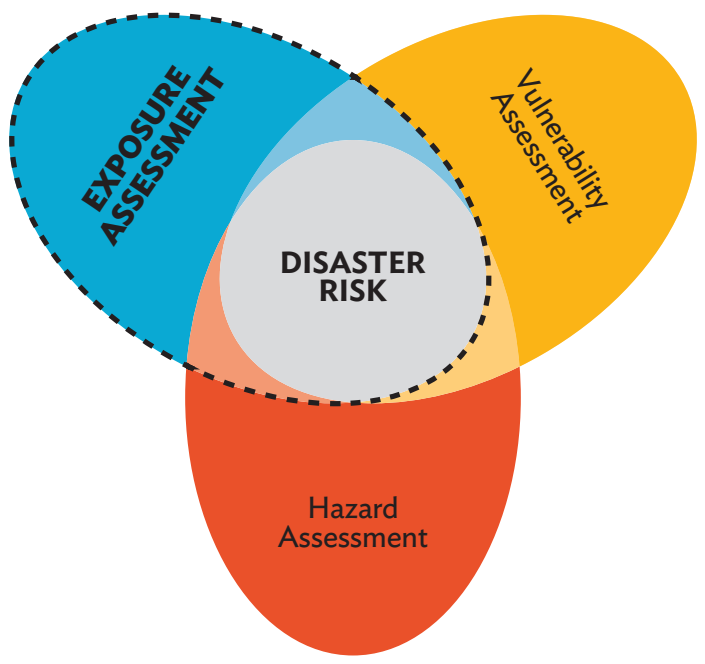

Source: ADB.

Identifying elements exposed to natural hazards is the second step of the DRA (Figure A1.3). Exposure is determined by overlaying spatial data on people and assets with information on natural hazards and can be done at various scales depending on the purpose of a DRA. For instance, footprints of a group of buildings (i.e., the spatial ground-floor parameters) can be overlaid with a landslide hazard map to analyze the nature and level of exposure to landslides. This process requires georeferenced inventories of assets. These assets may range from individual structures (e.g., power utilities) over limited areas to entire municipalities or regions (represented by groups of buildings, lifeline infrastructure, etc.). Assets also need to be valued to facilitate quantification of disaster risk in monetary terms, as necessary, for instance to inform decisions concerning the fiscal management of disaster risk (step 4). Assets should be valued at their replacement cost, not at their current market or depreciated book value. Table A1.3 provides an overview of appropriate mapping scale(s) for different types of exposure mapping. ${ }^{4}$

4 The scales noted here are slightly different than those indicated for hazard mapping because analyzing exposure requires a larger scale to accommodate more detail. 
Table A1.3: Scale(s) of Exposure Mapping

\begin{tabular}{|c|c|c|c|c|}
\hline \multirow{2}{*}{$\begin{array}{c}\text { Elements at Risk } \\
\text { Type(s) }\end{array}$} & \multicolumn{4}{|c|}{ Scale } \\
\hline & $\begin{array}{c}\text { Low } \\
<1: 100,000\end{array}$ & $\begin{array}{l}\text { Medium } \\
\text { 1:50.000 }\end{array}$ & $\begin{array}{l}\text { Large } \\
\text { 1:10,000 }\end{array}$ & $\begin{array}{l}\text { Very large } \\
>1: 10,000\end{array}$ \\
\hline $\begin{array}{l}\text { Transportation } \\
\text { networks }\end{array}$ & $\begin{array}{l}\text { Major transportation } \\
\text { networks }\end{array}$ & $\begin{array}{l}\text { Road and railway } \\
\text { networks with } \\
\text { high traffic } \\
\text { density }\end{array}$ & $\begin{array}{l}\text { National } \\
\text { transportation } \\
\text { networks and traffic } \\
\text { data }\end{array}$ & $\begin{array}{l}\text { All networks } \\
\text { with detailed } \\
\text { engineering and } \\
\text { traffic data }\end{array}$ \\
\hline Energy, water, etc. & $\begin{array}{l}\text { Main power } \\
\text { generation facilities } \\
\text { and reservoirs }\end{array}$ & $\begin{array}{l}\text { Main water } \\
\text { or electricity } \\
\text { networks, etc. }\end{array}$ & $\begin{array}{l}\text { Secondary } \\
\text { distribution } \\
\text { networks: } \\
\text { water, } \\
\text { wastewater, } \\
\text { electricity, } \\
\text { communication, } \\
\text { etc. }\end{array}$ & $\begin{array}{l}\text { Local networks } \\
\text { and related } \\
\text { facilities (micro- } \\
\text { hydropower } \\
\text { stations, etc.) }\end{array}$ \\
\hline Buildings & $\begin{array}{l}\text { Number of buildings } \\
\text { by municipality/ } \\
\text { district }\end{array}$ & $\begin{array}{l}\text { Buildings } \\
\text { by broad } \\
\text { categorization } \\
\text { (residential, } \\
\text { public, } \\
\text { commercial, } \\
\text { industrial) }\end{array}$ & $\begin{array}{l}\text { Buildings by finer } \\
\text { categorization: } \\
\text { use, height, type of } \\
\text { building materials }\end{array}$ & $\begin{array}{l}\text { Individual } \\
\text { building use, } \\
\text { construction } \\
\text { materials, design, } \\
\text { age, height, etc. }\end{array}$ \\
\hline Population & $\begin{array}{l}\text { By municipality: } \\
\text { population, density, } \\
\text { age, } \\
\text { gender }\end{array}$ & Same by ward & $\begin{array}{l}\text { By mapping unit } \\
\text { (i.e., zones of } \\
\text { homogenous land- } \\
\text { use/ building types): } \\
\text { population density } \\
\text { (daytime/ night), } \\
\text { age, gender }\end{array}$ & $\begin{array}{l}\text { People per } \\
\text { building: } \\
\text { day time/night, } \\
\text { income group, } \\
\text { age, } \\
\text { gender, ethnicity, } \\
\text { etc. }\end{array}$ \\
\hline Land Use & $\begin{array}{l}\text { Regional economic } \\
\text { production: } \\
\text { type of economic } \\
\text { activities (agriculture, } \\
\text { mining, forestry, etc.) }\end{array}$ & $\begin{array}{l}\text { Same by } \\
\text { municipality }\end{array}$ & $\begin{array}{l}\text { By mapping unit: } \\
\text { employment rate, } \\
\text { main income types } \\
\text { and sources }\end{array}$ & $\begin{array}{l}\text { By building: } \\
\text { employment, } \\
\text { businesses, } \\
\text { income, etc. }\end{array}$ \\
\hline
\end{tabular}

Source: Adapted from van Westen et al. (2011, 4-5).

In the analysis of exposure, buildings occupy a central position since exposed buildings also reveal the exposure of other elements. For instance, if residential buildings in a specific location are exposed to earthquakes, the people occupying these buildings are exposed too. The same is true for services or businesses. If a building fails or suffers major damage, people get injured or killed. The level of damage also impacts the functionality or continuity of services and economic activities undertaken in or from these structures. Therefore, many DRAs focus on the analysis of buildings, taking into account structural types 
and heights, construction materials, type of soil on which they are built, age, usage, and overall condition. There are two important variables in the relationship between buildings and natural hazard: (i) different types of natural hazard have different impacts on buildings; and (ii) different types of building will suffer differing degrees of damages from a given type of natural hazard.

Buildings are often analyzed by group, that is, classified into residential, commercial, and public buildings, and according to type of construction material. Analysis of the exposure and vulnerability of each building individually would require detailed structural assessments. This is extremely time-consuming, even under optimal resourcing conditions. Only critical and mass occupancy facilities, such as schools, hospitals, power utilities, dams, and water reservoirs, are typically assessed individually.

Land-use information is a critical input in exposure mapping because it supports the analysis of buildings by group. Building stock, infrastructure, and other asset databases are also important. The units of analysis or mapping can then be arranged according to the classification of land use to facilitate the analysis of exposure. An example of such classification on urban land use is presented in Table A1.4, adapted from the HAZUS methodology. ${ }^{5}$

Table A1.4: Urban Land-Use Inventory

\begin{tabular}{|c|c|}
\hline Occupancy Class & Example \\
\hline \multicolumn{2}{|c|}{ Residential } \\
\hline Squatter & Low-income houses in urban slums \\
\hline Small single & Small single houses mostly in rows \\
\hline Moderate single & Moderately sized single family dwellings \\
\hline Large single & Large freestanding houses \\
\hline Multistory & Multistory apartment blocks \\
\hline \multicolumn{2}{|c|}{ Commercial } \\
\hline Business & Commercial offices \\
\hline Hotel & Hotels, guesthouses \\
\hline Market & Market areas \\
\hline Shop & Shops and shopping malls \\
\hline \multicolumn{2}{|c|}{ Industrial } \\
\hline Hazardous industries & Hazardous storage or manufacture \\
\hline Nonhazardous industries & Nonhazardous industries \\
\hline Warehouses & Warehouses and workshops \\
\hline \multicolumn{2}{|c|}{ Institutional } \\
\hline Fire & Fire brigade \\
\hline Hospital & Hospitals/health clinics \\
\hline Office & Institutional offices \\
\hline Police & Police stations \\
\hline School & Schools, universities \\
\hline
\end{tabular}

5 HAZUS software has been developed by the Federal Emergency Management Agency for use in the United States. It is based upon a national standardized DRA methodology that requires adaptation for use in other development and disaster risk contexts. 


\begin{tabular}{|c|c|}
\hline \multicolumn{2}{|c|}{ Public Buildings } \\
\hline Cultural buildings & Theatres, museums, etc. \\
\hline Religious buildings & Temples, mosques, churches, etc. \\
\hline Electricity/water & Buildings related to electricity/water supply \\
\hline Cemetery & Cemeteries \\
\hline \multicolumn{2}{|c|}{ Recreational } \\
\hline Flat area & Flat area or football field \\
\hline Park & Park areas \\
\hline Stadium & Sport stadium \\
\hline \multicolumn{2}{|c|}{ Vacant areas with no buildings } \\
\hline Car & Car parks and bus station \\
\hline Construction & Vacant areas prepared for construction \\
\hline Shrubs & Vacant areas with shrubs, trees, and grass \\
\hline River & Rivers, waterways \\
\hline Damaged & Area recently damaged by hazard events \\
\hline
\end{tabular}

Source: Adapted from van Westen et al. (2011).

While there are an increasing number of open access databases on natural hazards and exposure (Box A1.2), project-focused risk assessments at the subnational level may need to identify additional, reliable data from other sources such as governments and research institutions to generate greater accuracy. If these data are not already organized in a single database, finding and then preparing data to be integrated into possible models is time-consuming and costly. Appendix 2 includes a list of open spatial data sources on population and assets. 


\section{Box A1.2: Open Access Data}

Over the past decade, there has been an increasing move to make risk data and information accessible. Instead of just publishing a disaster risk assessment report, the underlying data on hazards, exposure, and so forth are made freely available for further use and manipulation. This approach has the added potential to facilitate the updating of risk data in dynamically changing contexts, particularly in urban settings.

Initiatives include the Open Data for Resilience Initiative (Open DRI) established by the Global Facility for Disaster Reduction and Recovery of the World Bank. Open DRI helps governments and their partners catalogue existing stocks of relevant data through geospatial catalogues and provides communities with an opportunity to participate in mapping their exposure. As of May 2017, Open DRI covered the Pacific island countries, Afghanistan, Armenia, Bangladesh, Indonesia, the Kyrgyz Republic, Nepal, Pakistan, the Philippines, Sri Lanka, and Viet Nam.

However, opening data is not always smooth. There are often concerns over the release of potentially sensitive data and other data ownership and control issues. Meanwhile, participatory mapping can raise questions of data trustworthiness and credibility.

Source: ADB.

\section{STEP 3: VULNERABILITY ANALYSIS}

Vulnerability describes "the conditions determined by physical, social, economic and environmental factors or processes which increase the susceptibility of an individual, a community, assets or systems to the impacts of hazards" (UNISDR 2017).

Figure A1.4: Vulnerability Assessment

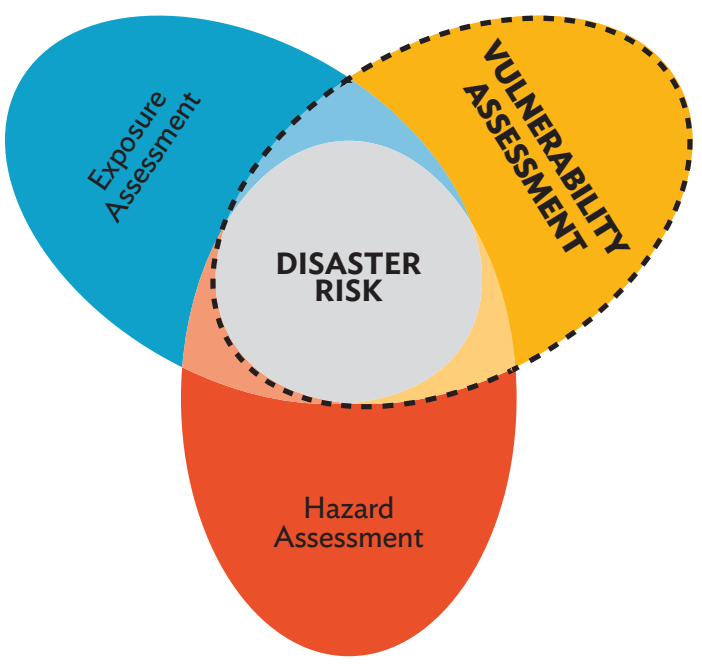

Source: ADB. 
Vulnerability assessments are performed on those elements that are determined to exhibit a certain degree of exposure ${ }^{6}$ to a natural hazard (Figure A1.4). The concept of vulnerability covers a range of physical, social, economic, and environmental features.

\subsection{Physical Vulnerability}

Physical vulnerability represents the potential direct impact of a natural hazard on the built environment and people. A physical vulnerability assessment can be done based either on empirical historical records of the performance of structures following past events or on modeling. The main methodologies and level of costs for physical vulnerability analysis are listed in Table A1.5.

Table A1.5: Methods and Costs of Physical Vulnerability Assessment

\begin{tabular}{|c|c|c|c|}
\hline Type & Method & Description & Level of Costs \\
\hline \multirow{3}{*}{$\begin{array}{l}\text { Empirical } \\
\text { Methods }\end{array}$} & $\begin{array}{l}\text { Analysis of historical } \\
\text { damage }\end{array}$ & $\begin{array}{l}\text { Based on historical damage statistics, } \\
\text { relating observed vulnerabilities to specific } \\
\text { natural hazard types and intensities }\end{array}$ & Lowest \\
\hline & Expert opinion & $\begin{array}{l}\text { Based on expert opinion on damage } \\
\text { potential for different structural types to } \\
\text { specific natural hazard types and intensities }\end{array}$ & \\
\hline & $\begin{array}{l}\text { Score assignment } \\
\text { (semiquantitative) }\end{array}$ & $\begin{array}{l}\text { Completion of questionnaire/score sheet } \\
\text { by a range of respondents to assign damage } \\
\text { to certain natural hazard level(s) }\end{array}$ & \\
\hline \multirow{2}{*}{$\begin{array}{l}\text { Analytical } \\
\text { Methods }\end{array}$} & $\begin{array}{l}\text { Analytical modeling } \\
\text { for groups of assets }\end{array}$ & $\begin{array}{l}\text { Computer-based models to simulate } \\
\text { damage potential of groups of assets } \\
\text { according to design characteristics (e.g., } \\
\text { adobe, masonry, reinforced concrete) } \\
\text { from natural hazards of varying type and } \\
\text { intensity }\end{array}$ & \\
\hline & $\begin{array}{l}\text { Detailed analytical } \\
\text { modeling for individual } \\
\text { assets }\end{array}$ & $\begin{array}{l}\text { Modeled behavior of individual structures } \\
\text { and their specific design characteristics } \\
\text { in the event of a natural hazard of varying } \\
\text { type and intensity }\end{array}$ & Highest \\
\hline
\end{tabular}

Source: Adapted from van Westen et al. (2011) and Lang (2002).

Probabilistic modeling is significantly more expensive and time-consuming than an analysis of historical damage or a semiquantitative analysis such as score assignments (e.g., based on indicators pertaining to the height of buildings, structural typologies, etc.). Similarly, assessing the physical vulnerability of structures individually is far more costly per unit than assessing a group of buildings. However, individual assessments can be indispensable for key structures whose damage or rupture could have severe consequences, such as medium- to large-scale dams and major water reservoirs. 
The relationship between natural hazard intensity and resulting damage for a particular asset or group of assets in a defined geographical area can be quantified and expressed as vulnerability functions. These functions can be plotted as vulnerability curves, showing levels of damage for particular infrastructure or types of infrastructure for varying intensities of a natural hazard event, as illustrated for floods in Figure A1.5. An increasing number of countries are establishing vulnerability curves for various classes of assets. Once established, they facilitate the processing of large quantities of data to examine the vulnerability of cities, regions, and entire countries.

Figure A1.5: Vulnerability Functions for Floods

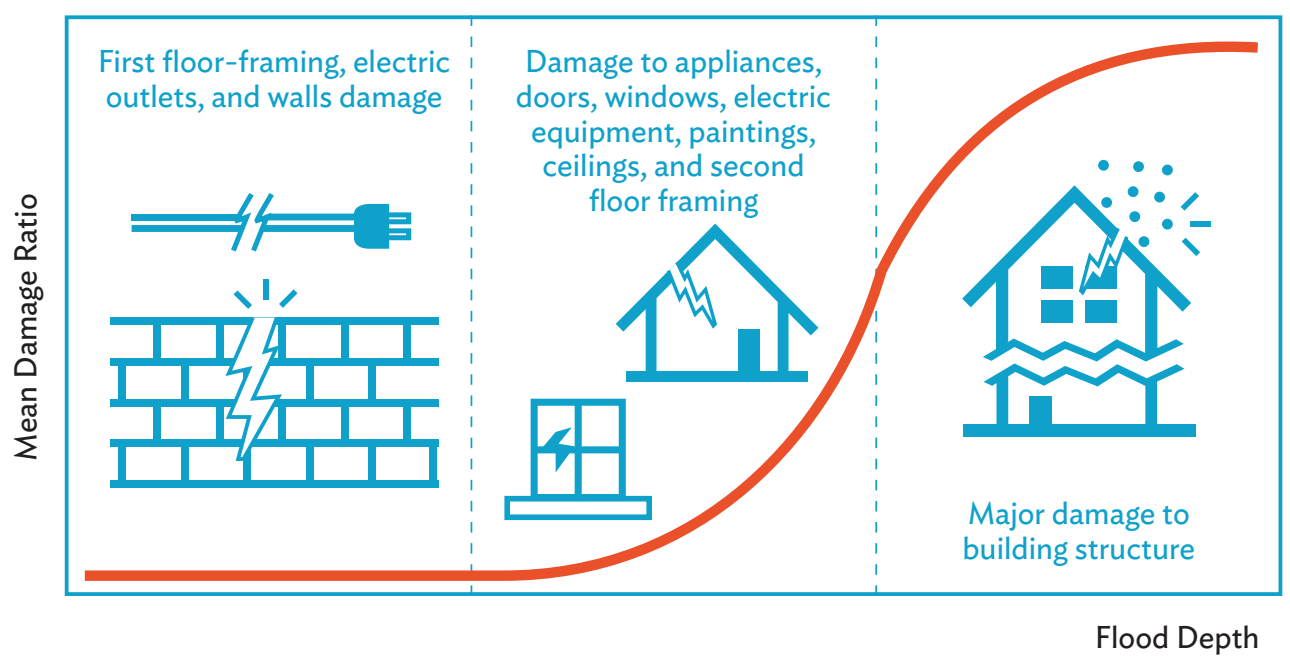

Source: ADB (2015).

The physical vulnerability of a population is closely tied to the analysis of structural vulnerability. Simulation of human loss estimates in the form of deaths and injuries is based on parameters representing the building damage potential and occupancy rates at different times of the day. In other words, the percentage of people presumed inside various structures will determine the physical vulnerability of the population to a particular natural hazard of specified intensity occurring at particular times of the day or night. This type of analysis is most commonly run for hazards with widespread destructive potential, such as earthquakes, tropical cyclones, and major floods.

\subsection{Social, Economic, and Environmental Vulnerability}

The analysis of social, economic, and environmental vulnerability requires an understanding of the level of capacity to adapt against, prepare for, cope with, and recover from the effects of a particular natural hazard. In general, capacity is contingent upon such diverse factors as land ownership, level of income, access to food and nutrition, the quality and accessibility of public services, education levels, local knowledge of natural hazards, coping mechanisms, financial preparedness (e.g., savings, insurance, contingency reserves), and governance arrangements. The analysis of these types of vulnerability is usually based on indicators. These indicators can be hazard specific or cover a range of hazards. For instance, the availability of crop insurance is typically hazard specific (floods, drought), whereas the level of access to emergency services would be relevant in determining vulnerability to almost all natural hazards. Sample vulnerability and capacity indicators are presented in Table A1.6. Defining the most appropriate indicator(s) is part of each analysis. Indicators should be selected and fine-tuned according to the type of natural hazard under investigation, assessment objectives, scale, and socioeconomic context. 
Table A1.6: Vulnerability and Capacity Indicators

\begin{tabular}{|c|c|c|}
\hline $\begin{array}{l}\text { Vulnerability/ } \\
\text { Capacity }\end{array}$ & Indicator Name & Indicator \\
\hline \multicolumn{3}{|c|}{ Vulnerability } \\
\hline Demographic & $\begin{array}{l}\text { Age/ gender distribution } \\
\text { Population density } \\
\text { Access to basic services }\end{array}$ & $\begin{array}{l}\text { Population by age group; female/male ratio } \\
\text { People per square kilometer } \\
\% \text { of homes with access to water, sanitation, } \\
\text { electricity, etc. }\end{array}$ \\
\hline Social & $\begin{array}{l}\text { Poverty level } \\
\text { Literacy } \\
\text { Decentralization }\end{array}$ & $\begin{array}{l}\% \text { of residents below poverty line } \\
\% \text { of adult population who read and write } \\
\text { Portion of self-generated/self-administered } \\
\text { budget }\end{array}$ \\
\hline Economic & $\begin{array}{l}\text { Local resource base } \\
\text { Diversification of income } \\
\text { Small businesses } \\
\text { Accessibility }\end{array}$ & $\begin{array}{l}\text { Local government budget } \\
\text { Number of economic sectors/employment } \\
\text { opportunities } \\
\% \text { of businesses with < } 20 \text { staff } \\
\text { Number of interruptions of road access in past X } \\
\text { years }\end{array}$ \\
\hline Environmental & $\begin{array}{l}\text { Forested area } \\
\text { Degraded land } \\
\text { Overused land }\end{array}$ & $\begin{array}{l}\% \text { of area covered with forest } \\
\% \text { of area that suffers erosion/desertification, etc. } \\
\% \text { of land/pastures that is environmentally } \\
\text { degraded }\end{array}$ \\
\hline \multicolumn{3}{|c|}{ Capacity } \\
\hline $\begin{array}{l}\text { Urban and } \\
\text { Physical } \\
\text { Planning }\end{array}$ & $\begin{array}{l}\text { Land-use planning } \\
\text { Building codes } \\
\text { Retrofitting } \\
\text { Preventive structures (dams, } \\
\text { drainage channels, etc.) } \\
\text { Environmental management }\end{array}$ & $\begin{array}{l}\text { Enforced risk-sensitive land use or zoning } \\
\text { Appropriate applied building codes } \\
\text { \% of retrofitted or reinforced buildings } \\
\text { Status and maintenance } \\
\text { Applied nature protection/ preservation } \\
\text { regulations }\end{array}$ \\
\hline Social & $\begin{array}{l}\text { Emergency drills and simulations } \\
\text { Local risk or emergency } \\
\text { management groups }\end{array}$ & $\begin{array}{l}\text { Frequency and scale of programs } \\
\text { Frequency of drills and levels of participation } \\
\text { Grade of organization/training, etc. }\end{array}$ \\
\hline
\end{tabular}




\begin{tabular}{|c|c|c|}
\hline Economic & $\begin{array}{l}\text { Local emergency funds } \\
\text { Access to national/international } \\
\text { funds } \\
\text { Insurance market }\end{array}$ & $\begin{array}{l}\text { \% of local budget } \\
\text { Historical records on release of government } \\
\text { disaster response funds } \\
\text { Historical records on international disaster } \\
\text { assistance, including recovery loans } \\
\text { Level of insurance cover by natural hazard type }\end{array}$ \\
\hline $\begin{array}{l}\text { Emergency } \\
\text { Management }\end{array}$ & $\begin{array}{l}\text { Risk map } \\
\text { Emergency plan } \\
\text { Emergency committee } \\
\text { Early warning system }\end{array}$ & $\begin{array}{l}\text { Availability, scale, coverage of map } \\
\text { Frequency of updating/dissemination } \\
\text { Frequency of meetings } \\
\text { Mock exercises/records on activation }\end{array}$ \\
\hline
\end{tabular}

Sources: Adapted from Hahn et al. (2003); Bollin and Hidajat (2006).

Social, economic, and environmental analyses are based predominantly on qualitative methods but also utilize semiquantitative tools such as weighted scales, attaching varying values to different indicators. The latter are particularly relevant in establishing indices to identify the most vulnerable communities across a range of locations and to identify the most vulnerable groups and locations within a community. These indices can also be translated into maps. Qualitative research can also be undertaken to investigate how people have historically coped with different natural hazard events and to explore whether their coping strategies are still valid or have been turned ineffective by various environmental, social, or economic changes (e.g., outmigration weakening the social fabric of a community) (Box A1.3).

\section{Box A1.3: Participatory Vulnerability Assessments}

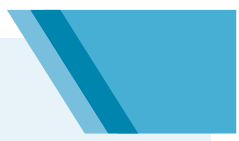

Local and indigenous knowledge and risk perception are considered crucial in designing adequate and sustainable disaster risk reduction (DRR) solutions at the community level. The local population often has specific knowledge of the triggers and locations of hazard events, and the local chain of causes and effects that influence vulnerability. Local knowledge includes but is not limited to

- historical disaster events and impacts, including small-scale and localized disasters;

- factors contributing to vulnerability; and

- coping and adaptive strategies.

Local participatory analysis strives to collect information and involve communities in the design of DRR activities. Participatory analysis in selected locations can be undertaken as a component of a wider risk assessment to further examine vulnerability and go into more depth on key issues. It can also be undertaken as a stand-alone exercise, for instance to inform community or urban development projects. The length of assessments varies but sufficient time needs to be allowed to identify and mobilize participation from key stakeholders.

Source: ADB. 


\section{STEP 4: DISASTER RISK ASSESSMENT}

Disaster risk assessment is a "qualitative or quantitative approach to determine the nature and extent of disaster risk by analyzing potential hazards and evaluating existing conditions of exposure and vulnerability that together could harm people, property, services, livelihoods and the environment on which they depend" (UNISDR 2017).

Figure A1.6: Disaster Risk Assessment

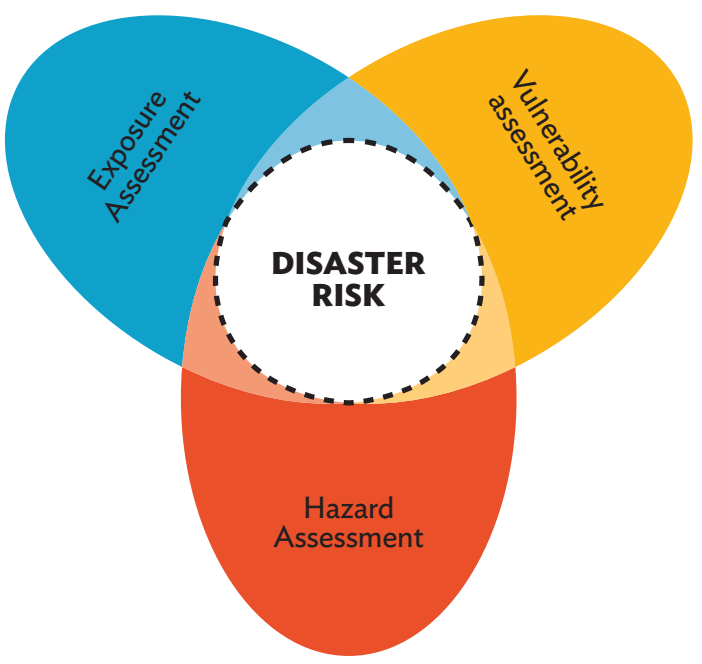

Source: ADB.

DRA pulls the three components together, determining the relationship between natural hazard, exposure, and vulnerability (Figure A1.6). DRA can be undertaken using quantitative or qualitative methodologies and the implied disaster risk.

\subsection{Quantitative Disaster Risk Assessment}

Quantitative DRAs are mostly used to analyze the risk of physical damage and loss and require considerable time and resources. They may be deterministic or probabilistic and express risk in the form of probabilities or expected losses.

Deterministic DRAs focus on the analysis of particular natural hazard scenarios or events, based on the behavior of past events. For example, a deterministic risk model may show the impact of flooding that would result from a particular rainfall event or the amount of losses that would occur due to a particular magnitude earthquake at a specified point along a fault line.

Probabilistic approaches rely on modeled natural hazard catalogs over thousands of years to assess the probability of events of varying magnitude in a given location. They are becoming increasingly robust due to improved modeling techniques and are particularly common in seismic and tropical cyclone risk modeling. Probabilistic risk assessments involve significant modeling work and are therefore costly and time-consuming. 
Quantitative risk estimations can be conducted for

- physical assets: partial or total damage to infrastructure, buildings and other assets;

- economic losses: direct damage from the impact of a natural hazard expressed in monetary terms and the resulting indirect losses; and

- population: morbidity and mortality risk in a population.

Quantitative DRA generates data on probable maximum losses from hazard events with varying return periods. These can be plotted as loss curves, as illustrated in Figure A1.7 for typhoon risk in Hue, Viet Nam. The horizontal axis represents the frequency of loss due to the natural hazard and the vertical axis the severity of impact in monetary terms. The curve indicates the frequency with which natural hazard events will reach particular levels of loss. At the low end of the curve, very frequent and less damaging natural hazard events are reflected, such as regularly recurring floods or low intensity storms. The resulting relief, early recovery, and reconstruction needs are usually within the financial capacity of the relevant entity because the impacts are minor. At the upper end of the curve, very severe but infrequent disaster events are reflected.

Figure A1.7: Loss Curve for Typhoon Risk - Hue, Viet Nam

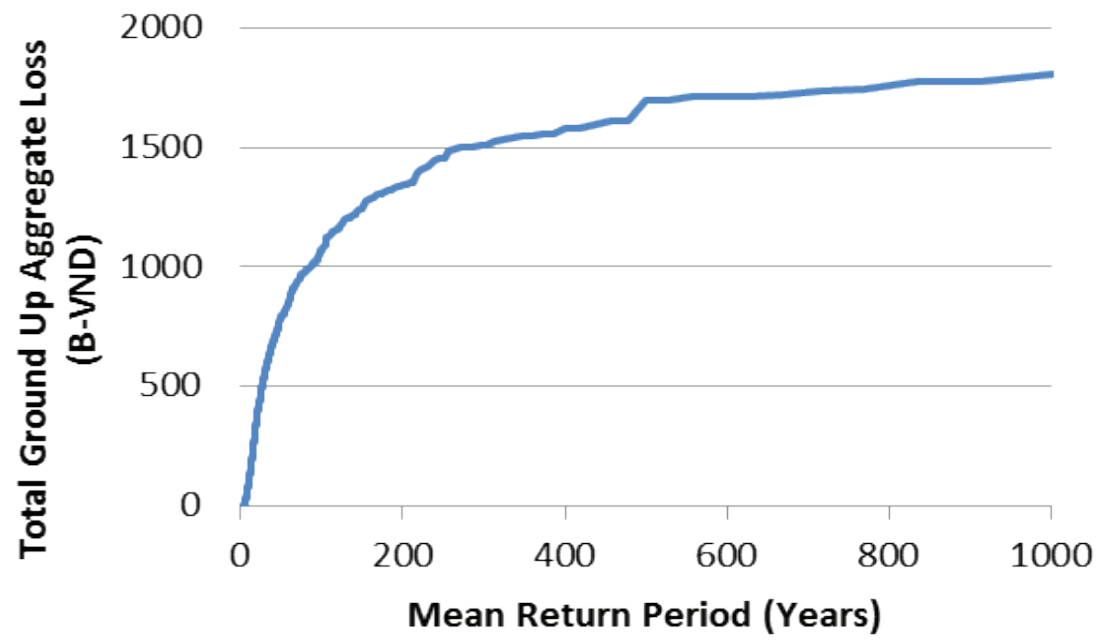

Source: ADB (2015).

Probable maximum loss data can also be used to determine average annual loss - that is, average annual expected losses over a very long period or over particular ranges of hazard frequency. These data are also important in informing decisions concerning the fiscal management of disaster risk, for instance as the pricing of disaster insurance, as well as in the structural design of infrastructure.

\subsection{Qualitative and Semiquantitative Disaster Risk Assessment}

Qualitative DRA methods are used when there are time and resource constraints, in cases where there is insufficient information regarding the frequency and intensity of a natural hazard, or when the exposed assets under investigation or their level of vulnerability are difficult to quantify. This applies in particular to DRAs focusing on social dimensions of disaster risk at any level and on economic and environmental dimensions of household and community disaster risk. 
Instead of identifying absolute values for the probability of degrees of expected loss, qualitative risk assessments express the risk in relative terms, distinguishing between, say, insignificant, minor, medium, major, and catastrophic levels of risk. Each class can then be associated with a proposed type of action to reduce the risk. Table A1.7 illustrates an approach to qualifying risk proposed by the Australian Geomechanics Society.

Table A1.7: Example of a Qualitative Risk Assessment Matrix

\begin{tabular}{|c|c|c|c|c|c|}
\hline \multirow{2}{*}{ Likelihood } & \multicolumn{5}{|c|}{ Consequences } \\
\hline & Catastrophic & Major & Medium & Minor & Insignificant \\
\hline Almost certain & $\mathrm{VH}$ & $\mathrm{VH}$ & $\mathrm{H}$ & $\mathrm{H}$ & M \\
\hline Likely & $\mathrm{VH}$ & $\mathrm{H}$ & $\mathrm{H}$ & M & L-M \\
\hline Possible & $\mathrm{H}$ & $\mathrm{H}$ & M & L-M & $V L-L$ \\
\hline Unlikely & $\mathrm{M}-\mathrm{H}$ & M & L-M & $V L-L$ & $\mathrm{VL}$ \\
\hline Rare & $M-L$ & L-M & $V L-L$ & $V L$ & $\mathrm{VL}$ \\
\hline Not credible & $\mathrm{VL}$ & $\mathrm{VL}$ & $\mathrm{VL}$ & $\mathrm{VL}$ & $\mathrm{VL}$ \\
\hline
\end{tabular}

Note: $\mathrm{VH}=$ very high; $\mathrm{H}$ = high; $\mathrm{M}=$ medium; $\mathrm{L}=$ low and $\mathrm{VL}=$ very low risks.

Source: Australian Geomechanics Society (2000).

The matrix translates the risk formula into qualitative terms; that is, it combines the likelihood of the hazard with its consequences, as determined by the level of the exposure and vulnerability, and assigns a level of risk accordingly. This means that the highest level of risk is attributed to events that have the highest level of likelihood and would cause the largest damage.

Such risk matrices can be established on the basis of (i) existing data on natural hazards, exposure, and vulnerability; (ii) expert opinions; and/or (iii) the results of, participatory assessments at the community level. Terms such as "catastrophic" consequences or "almost certain" for the likelihood of a hazard need to be defined as precisely as possible in quantitative terms. For instance, a high degree of likelihood could be defined as an event that will occur once every 5 years, a medium likelihood event from 5 to 50 years, and a low likelihood event from 500 to 5,000 years.

The undisputable advantage of qualitative assessments is that they are relatively fast and inexpensive. They are particularly suitable for local-level risk assessments. The disadvantages lie in a relatively higher degree of uncertainty, particularly with regard to less frequent natural hazards that are not well documented.

Semiquantitative assessments assign weights to certain likelihood and loss criteria resulting in hazard and vulnerability indexes. The indexes are further combined to determine levels of risk expressed in numbers. These numbers have no absolute meaning. Instead, they are only relative indicators. The advantage of semiquantitative assessments is that they can cover multiple natural hazard and vulnerability criteria to define and rank risk. Geographic information system applications facilitate the classification, weighting, and integration of relevant data and indices, as well as their presentation in the form of maps. 
A semiquantitative approach can be applied at any scale but is particularly suitable for assessments of municipalities and districts in urban development programs. It is commonly used (i) to establish an initial overview of key natural hazards and disaster risks; (ii) when the type and level of investment or disaster risk does not justify a quantitative risk assessment; and (iii) where there is insufficient quantitative data. Many global risk studies and indices have used a semiquantitative approach. Examples include the disaster risk index developed by the United Nations Office for Disaster Risk Reduction (UNISDR 2015) and the global hotspots analysis (World Bank 2005).

\section{References}

ADB. 2015. Strengthening City Disaster Risk Financing in Viet Nam. Manila.

ADB. 2017a. Natural Hazard Data: A Practical Guide. Manila.

ADB. 2017b. Climate Change Strategic Framework 2017-2030: Enhanced Actions for Low Greenhouse Gas Emissions and Climate-Resilient Development. Manila.

Australian Geomechanics Society. 2000. Landslide Risk Management Concept and Guidelines. Australian Geomechanics. Vol. 35 No. 1.

Bollin, C., and R. Hidajat. 2006. Community-Based Disaster Risk Index: Pilot Implementation in Indonesia. In: J. Birkmann (ed.) Measuring Vulnerability to Natural Hazards: Towards Disaster Resilient Societies. Tokyo and New York: United Nations University Press.

Eychaner, J.H. 2015. Lessons from a 500-Year Record of Flood Elevations. Association of State Floodplain Managers, Technical Report 7. Madison, WI: Association of State Floodplain Managers.

Hahn, H., J.C. Villagrán De León and R.Hidajat. 2003. Indicators and Other Disaster Risk Management Instruments for Communities and Local Governments. Washington, DC: Inter-American Development Bank.

Intergovernmental Panel on Climate Change (IPCC). 2012. Managing the Risks of Extreme Events and Disasters to Advance Climate Change Adaptation. Special Report on Managing the Risks of Extreme Events and Disasters to Advance Climate Change Adaptation (SREX). C.B Field et al (eds.). Cambridge, UK and New York: Cambridge University Press.

- - - 2013. Climate Change 2013: The Physical Science Basis. Contribution of Working Group I to the Fifth Assessment Report of the Intergovernmental Panel on Climate Change. T.F. Stocke et al (eds.). Cambridge, UK and New York: Cambridge University Press.

Lang, K. 2002. Seismic Vulnerability of Existing Buildings. Institute of Structural Engineering, ETH Zurich, Report No. 273. Zurich: Institute of Structural Engineering, Swiss Federal Institute of Technology.

United Nations Office for Disaster Risk Management (UNISDR). 2015. Making Development Sustainable: The Future of Disaster Risk Management. Global Assessment Report on Disaster Risk Reduction. Geneva.

- - - 2017. Terminology. https://www.unisdr.org/we/inform/terminology (accessed 12 March 2017).

van Westen, C.J., D. Alkema, M.C.J. Damen, N. Kerle, and N.C. Kingma. 2011. Multi-hazard Risk Assessment. Disaster Education Course. Guide Book. United Nations University \& ITC School on Geo-Information Management.

World Bank. 2005. Natural Disaster Hotspots: A Global Risk Analysis. Washington, DC. 


\section{Appendix 2: Spatial Data Requirement for Disaster Risk Assessment}

\section{A. Types and Suitability of Spatial Data}

All three components determining disaster risk-natural hazard, exposure, and vulnerability-are spatial in nature, meaning that they relate to a specific geographical location, size, and extent. Moreover, a disaster risk assessment (DRA) may explicitly include a mapping of components to help facilitate the visualization and communication of risk assessment results to a wider audience. Spatial image data types include georeferenced maps, aerial photos, and satellite images. Relevant data should be digitized and introduced into geographic information system (GIS) software for comprehensive analysis and disaster risk modeling purposes. For instance, a DRA may overlay and analyze data on topography (Box A2.4), natural hazards, river networks, land use, and population density as well as on the built environment, such as housing, roads, factories, and other public and infrastructure.

\section{Box A2.4: Digital Elevation Models}

Certain hazards such as landslides, floods, or tsunamis require time-sensitive data on elevation above a defined area (such as sea levels during ebbs and floods) to increase the accuracy of hazard and risk assessment. Digital elevation models can, for instance, show altitude(s) across a coastline and against various distances from that line, or the steepness and orientation of slopes. Data for digital elevation models can be collected from ground surveys (with a global positioning system, which is suitable for small-scale hazards in particular, or by using drones), topographical maps, and stereoscopic aerial or satellite images.

Source: van Westen et al. (2011).

The suitability of different spatial data types varies depending on the natural hazard(s) and exposed assets under investigation and the intended use of the data. Natural hazards can be very localized and small or very extensive, affecting large areas. There can be a significant distance between the source of the hazard, such as glacial lakes, and the areas affected. Accordingly, spatial data need to suit both the specifics of the natural hazard (see also companion practical guide on natural hazard assessment [ADB 2017]) and the exposed element(s) under investigation. For instance, investigating flooding along a river basin only requires low resolution imagery of a river basin at different times across the year, whereas mapping of exposed buildings and assets requires high-resolution data.

There can be significant disparity between suitable and actually available or accessible spatial data for DRAs. For instance, some countries limit the sale or use of images of their territory for security reasons. Some thematic exposure data layers, such as population and housing census data, may only be available in aggregated form. Local, high-resolution data, including disaster impact statistics on smaller-scale events, are typically the hardest to find. Moreover, relevant data are often fragmented across several organizations and stored in different, often incompatible, formats or not digitized at all. It is important that consultants hired to perform a DRA have experience in working around such obstacles. 
Processing spatial data requires adequate software (i.e., GIS or image analysis software) and expertise. While there are already open or low-cost sources for GIS and more basic types of image analysis, expertise in use of the software is also required, particularly for more advanced data processing, such as the integration of natural hazard and vulnerability parameters or modeling.

The cost of spatial image data from commercial providers can be quite significant, but there are an increasing number of open or low-cost sources of data as well. Google Earth, for instance, provides raster pictures of recent high-resolution satellite images. Google Earth Pro, which comes at a low cost, allows the storage of high-resolution pictures and their integration with other spatial data in a GIS, making it particularly suitable for detailed natural hazard and exposure mapping. The suitability of Google Earth for more sophisticated risk modeling and manipulation is, however, limited.

Thanks to efforts of some international and scientific organizations, there are a growing number of global thematic datasets that are improving in coverage and resolution and are available for use in determining exposure as part of a DRA.

\section{B. Online Natural Hazard Screening and Disaster Risk Visualization Tools}

\section{World Bank's Climate and Disaster Risk Screening Tools}

https://climatescreeningtools.worldbank.org/about-the-tools

The World Bank's climate and disaster risk screening tools are self-paced tools that provide high-level screening in the early stages of project development. They support the consideration of short- and longterm climate and disaster risks in national or sector planning and project-level investments in agriculture, water, roads, coastal flood protection, energy, health, and other development sectors. Rather than providing detailed analysis or specific resilience measures, the tools help determine the need for further studies, consultation, or dialogue in the course of project design and planning.

\section{Think Hazard!}

https://www.gfdrr.org/thinkhazard---new-simple-platform-understanding-disaster-risk

Think Hazard! is an online platform managed by the World Bank and Global Facility for Disaster Reduction and Recovery containing information on eight different types of hazards in all geographical areas with a resolution of 50 square kilometers. The interpretation of the hazard environment is nontechnical and the tool generates generic (non-sector-specific) recommendations for incorporating DRM into project planning and design. Furthermore, the tool provides a link to any existing relevant assessments and reports for each country and hazard for further consultation.

\section{United Nations Environment Programme Global Risk Data Platform PREVIEW}

http://preview.grid.unep.ch/index.php?preview=home\&lang=eng

The Global Risk Data Platform PREVIEW is a multiagency effort to share spatial data information on disaster risk from natural hazards across the globe. It offers a more sophisticated tool than AWARE or Think Hazard! to visualize, download, or extract data on past hazard events, human and economic exposure, and risk from natural hazards.

The platform covers tropical cyclones and related storm surges, drought, earthquakes, biomass fires, floods, landslides, tsunamis, and volcanic eruptions. It allows the visualization of data on natural hazards, exposure, and disaster risk. Users can perform zooms, pan to a particular area, and add different layers of 
general data, including cities or national parks. Different backgrounds can be chosen to highlight different components, such as population distribution, gross domestic product per capita, elevation, and land cover. Layers of natural hazards can be added for both events and yearly average for tropical cyclones, droughts, earthquakes, biomass fires, floods, landslides, and tsunamis.

\section{Open Source/Low-Cost Spatial Base Data and Spatial Imagery Sources}

\section{Thematic Base Data (free)}

\section{Digital Chart of the World}

http://www.maproom.psu.edu/dcw/

The Digital Chart of the World is a global base map of international boundaries, coastlines, cities, airports, elevations, roads, railroads, water features, cultural landmarks, national boundaries, etc. Data are from $1991 / 92$ and therefore partly outdated. Searchable country and data layers are ready for selection and immediate downloading.

\section{Geocommunity}

http://data.geocomm.com/

Geocommunity is another source for digital georeferenced base data, adding satellite imagery.

\section{Food and Agriculture Organization of the United Nations (FAO) Geonetwork} http://www.fao.org/geonetwork/srv/en/main.home

Geonetwork covers base layers (e.g., boundaries, roads, rivers), thematic layers (e.g., protected areas), and backdrop images (e.g., World Forest 2000). Maps can be generated using searchable global and regional functions.

\section{Mountain Environment and Natural Resources Information Systems (MENRIS) http://rds.icimod.org}

The MENRIS system covers the Himalayan/Hindu Kush region including Bangladesh, Bhutan, the People's Republic of China, Nepal, and Pakistan. It is still in development and aims at bringing together data on meteorological and hydrological parameters, air pollution, ecological and climate change, status and changes in land use and land cover, biodiversity (including threats to biodiversity), floods and other natural hazards, and socioeconomic changes, generated by remote sensing, spatial analysis, and fieldwork. Datasets on land cover, glacial lakes, etc. are already available for Bhutan and Nepal.

\section{Images (Free and Low Cost)}

\section{Google Earth}

Google Earth includes typically high resolution, recently available satellite images but only in the form of raster pictures. Other available data layers can be added on top but the tool does not offer manipulation of imagery. With Google Earth Pro (for which a relatively modest license fee is charged), it is possible to save high-resolution pictures. These can then be integrated with other spatial data in a GIS. This can be useful for detailed risk mapping.

\section{Global Digital Elevation Models (DEM)/Shuttle Radar Topography Mission (SRTM)} http://www.jpl.nasa.gov/srtm/

SRTM contains data on nearly the entire globe at 90-meter resolution. Users can specify areas of interest. Due to the high resolution, the files for downloading can be quite large. 


\section{Advanced Spaceborne Thermal Emission and Reflection Radiometer (ASTER)}

ASTER data are available via the Earth Observing System Data Gateway (http://edcimswww.cr.usgs. gov/pub/imswelcome/), which also provides access to other data from satellites operated by the United States National Aeronautics and Space Administration (NASA) and National Oceanic and Atmospheric Administration (NOAA). Launched in 1999, the sensor carries 15 channels, with 4 bands at 15-meter resolution, 6 at 60 -meter resolution, and 5 at 90 -meter resolution, and provides images with excellent spatial details. Users can register for free or search as a guest. A faster way to check for available data is via the United States Geological Survey (USGS) Global Visualization Viewer (GLOVIS) (http://glovis.usgs. gov/), which provides a good graphical overview. ASTER data are charged out a relatively modest fee per scene.

\section{Moderate Resolution Imaging Spectroradiometer (MODIS) \\ http://modis-land.gsfc.nasa.gov}

MODIS is also NASA operated and complements ASTER. Like ASTER, the resolution of MODIS images is variable, but the coverage of MODIS is such that very large regions can be monitored daily. The data are particularly suited for vegetation studies (see http://edcdaac.usgs.gov/modis/dataproducts.asp). The data are free. An automatic system has set up at the University of Hawaii that uses MODIS data to map volcanic hotspots (http://modis.higp.hawaii.edu/).

\section{Landsat Multispectral Scanner (MSS)/Thematic Mapper (TM) Data \\ http://glovis.usgs.gov/}

Landsat can be searched using the GLOVIS tool mentioned earlier or the Global Landcover Facility (http://glcf.umiacs.umd.edu/index.shtml). Landsat has a resolution of 30 meters and is entirely free of cost, including for access to the archive. Files as in other databases have georeferenced information and can easily be integrated into a GIS program.

\section{SPOT Vegetation}

http://free.vgt.vito.be

Regular SPOT images are expensive, but data that are older than 3 months are available for free. The resolution of the vegetation data is 1.1 kilometers.

\section{Open Spatial Data Sources on Population and Assets}

\section{Population}

http://sedac.ciesin.columbia.edu/data/set/gpw-v4-population-density

Gridded population of the world covering population estimates for 2000, 2005, 2010, 2015, and 2020. A proportional allocation gridding algorithm, utilizing approximately 12.5 million national and subnational administrative units, is used to assign population values to 30 arc-second (approximately 1 kilometer) grid cells. The population density grids are created by dividing the population count grids by the land area grids. The pixel values represent persons per square kilometer.

\section{Building and capital stock}

http://www.nexus.globalquakemodel.org/ged4gem/posts

Building and population inventory using building type classifications with spatial, structural, and occupancy-related information. Suitable for tropical cyclone and earthquake exposure analysis. 


\section{Building stock/population/economic}

http://risk.preventionweb.net/capraviewer/main.jsp?tab=1\&mapcenter=13081127.270789,1869368.5554 314\&mapzoom $=3$

A ready-to-use analysis (rather than database) of exposure for the 2015 Global Assessment Report (UNISDR 2015) that covers a range of variables including population, capital stock (disaggregated into urban and rural), and economic indicators.

\section{Agriculture}

http://www.fao.org/gtos/atlas.html

AgroMetShell is a specific software toolbox developed by FAO for crop yield forecasting that facilitates the integration of spatial (map), tabular (spreadsheet), and unstructured (document) data and metadata. It allows data from various sources to be integrated and customized online maps to be produced.

\section{Exposure Data/National Level}

Key categories and potential sources of exposure data are indicated in the following table:

\begin{tabular}{|c|c|c|}
\hline Asset Categories & Explanation & Possible Sources \\
\hline Population & $\begin{array}{l}\text { Demographic numbers and } \\
\text { characteristics (age, gender, income, } \\
\text { etc.) }\end{array}$ & Census data from statistical offices \\
\hline Capital stock/buildings & $\begin{array}{l}\text { Building location, building materials, } \\
\text { replacement value, occupancy types } \\
\text { (residential, commercial, industrial, } \\
\text { administrative, etc.), etc. }\end{array}$ & $\begin{array}{l}\text { Census data (for residential) } \\
\text { Ministries of housing/economy/ } \\
\text { industry } \\
\text { Chambers of commerce }\end{array}$ \\
\hline Agriculture & $\begin{array}{l}\text { Crop production, yield, and acreage; } \\
\text { rain-fed and irrigated production; } \\
\text { livestock populations and } \\
\text { production; agricultural assets; land } \\
\text { use; land ownership }\end{array}$ & Ministries of agriculture \\
\hline Forestry & $\begin{array}{l}\text { Forest types, coverage, and } \\
\text { production }\end{array}$ & Ministries of forestry/environment \\
\hline Fisheries & $\begin{array}{l}\text { Fish farming, commercial fishing, } \\
\text { and processing assets }\end{array}$ & Ministries of agriculture/fisheries \\
\hline Transportation & $\begin{array}{l}\text { Road, rail, air, and other relevant } \\
\text { networks }\end{array}$ & Ministries of transport \\
\hline Utilities & $\begin{array}{l}\text { Power generation plants and } \\
\text { transmission and distribution } \\
\text { systems, water supply and } \\
\text { distribution systems, wastewater } \\
\text { systems, telecommunications }\end{array}$ & $\begin{array}{l}\text { Ministries of energy } \\
\text { Ministries of water/natural } \\
\text { resources } \\
\text { Ministries of communication } \\
\text { Urban planning agencies }\end{array}$ \\
\hline $\begin{array}{l}\text { Critical facilities with high } \\
\text { occupancy/losses }\end{array}$ & $\begin{array}{l}\text { Health care facilities, schools and } \\
\text { educational buildings, and public } \\
\text { buildings and offices }\end{array}$ & $\begin{array}{l}\text { Ministries of education, health, } \\
\text { interior, etc. }\end{array}$ \\
\hline
\end{tabular}




\section{References}

ADB. 2017. Natural Hazard Data: A Practical Guide. Manila.

United Nations Office for Disaster Risk Management (UNISDR). 2015. Making Development Sustainable: The Future of Disaster Risk Management. Global Assessment Report on Disaster Risk Reduction. Geneva.

van Westen, C.J., D. Alkema, M.C.J. Damen, N. Kerle, and N.C. Kingma. 2011. Multi-hazard Risk Assessment. Disaster Education Course. Guide Book. United Nations University \& ITC School on Geo-Information Management. 


\section{Appendix 3: Lead Disaster Risk Assessment Questions Focusing on Natural Hazards and Exposure}

This appendix provides potential questions which could be posed to determine the natural hazards to which an investment and/or wider project catchment area are exposed. They are recommended for use in the case of projects that do not require in-depth disaster risk assessments (Appendix 1, Step 4). They are particularly relevant in undertaking environmental impact assessments (EIAs) or risk assessment management plans (RAMPs) but can also be integrated into other assessments.

Further information on different types of natural hazard and on the identification and application of robust natural hazard data for use in integrating disaster risk considerations into the design of individual projects is provided in the companion practical guide on natural hazard assessment (ADB 2017).

Assessments of projects in disaster-prone areas should address two key issues:

- Potential destructive impact of a natural hazard on project investments

- Potential consequences of proposed project activities on exposure and vulnerability to natural hazards in the project area

Generic lead questions (to be adapted and modified for use in specific contexts) are:

1. What are the key natural hazards affecting the project area and what are the most exposed locations and settlements in their zones of influence? What is the intensity, geographical scale, and probability of occurrence of these hazards?

2. Is the proposed project site suitable in terms of localized factors influencing the intensity and probability of a natural hazard (e.g., land gradient, height, soil conditions)?

3. Will the project increase or decrease environmental processes that feed into disaster risk (e.g., desertification, deforestation, siltation of rivers, land degradation)? Some sector specific examples with regard to flooding are provided in Box A3.1.

\section{Box A3.1: Sector-Specific Checklist on Factors Impacting Flood Risk}

- Urban Development: Impact of urban development on water runoff

- Transport: Impact of road construction and associated infrastructure on natural drainage systems

- Agriculture: Impact on soil erosion and consequences for levels of water 
4. Will the project alter existing land-use patterns and increase or decrease exposure of communities to natural hazards (e.g., turning unproductive lands into agriculturally productive areas or opening up areas for settlement)?

5. Will the project affect the socioeconomic situation in the project area and what likely consequences will this have on exposure to natural hazards (e.g., decreasing migration from hazard-prone areas, promoting urbanization in hazard-prone areas)?

6. Is the disaster risk management (DRM) capacity in the project area sufficient to cope with the current and predicted levels of natural hazard frequency and intensity?

7. What, if any, are the key proposed DRM measures in view of the overall analysis of a natural hazard and exposure (e.g., changes in project design, the addition of environmental protection and/ or local emergency preparedness measures)?

\section{References}

ADB. 2017. Natural Hazard Data: A Practical Guide. Manila.

Benson, C., and J. Twigg. 2007. Tools for Mainstreaming Disaster Risk Reduction. Guidance Notes for Development Organizations. Geneva: ProVention Consortium. 


\section{Appendix 4: Lead Disaster Risk Assessment Questions Focusing on Community Vulnerability}

This appendix provides potential questions which could be posed to explore community vulnerability. They are recommended for use in the case of projects that do not require in-depth disaster risk assessments (Appendix 1, step 4). They are particularly relevant in undertaking poverty and social analysis and gender assessments but can also be integrated into other assessments.

Assessments of projects in hazard-prone areas should address two key issues:

- Potential destructive impact of a natural hazard on communities in the project catchment area with particular attention to women and ethnic minorities (also considering how this might affect project outcomes/ outputs)

- Potential consequences of proposed project investments on the vulnerability or resilience of communities to natural hazards with particular attention to women and ethnic minorities

Generic lead questions (to be adapted and modified for use in specific contexts) are:

1. What are the key natural hazards affecting the project area and what is their intensity, size, and frequency?

2. Which settlements/communities are most likely to be affected by these hazards (e.g., looking at physical exposure, historical damage data, poverty indices)?

3. What is the likely impact of a natural hazard on settlements, communities or groups (e.g., on people, livelihoods, ecosystems and assets, based on historical damage data, surveys, participatory research)?

4. What are the main reasons for community vulnerability?

5. What is the current capacity of communities to cope with natural hazard scenarios, for example, to predict, mitigate, respond or adapt to, and recover from natural hazard impacts?

6. How do gender roles feed into vulnerability and/or capacity? What has been the gender-specific impact of disasters?

7. How could the impact of a natural hazard event on communities affect project outcomes and outputs? Could disasters threaten the financial viability of the project?

8. What is the government's involvement in disaster risk management and what relevant information, services, or resources are available to communities (e.g., emergency services and response capacity; awareness raising, drills, and simulations; regulatory norms and codes for land use and construction; financial strategies for recovery)?

9. Do women and men and girls and boys have equal access to this information, and to services and resources that help reduce or buffer disaster impacts?

10. Is the current project design likely to have a negative or positive impact on the vulnerability of communities (e.g., is the new bridge seismically resilient and what possible cascading effects could result from its destruction)?

11. Could the project be adjusted/improved to increase community resilience or the resilience of particularly vulnerable groups? What are the key measures required in this regard and approximate costs? 


\section{Appendix 5: Examples of Structural and Nonstructural Disaster Risk Management Options in ADB's Key Sectors}

\begin{tabular}{|c|c|c|c|}
\hline Sector & Key Vulnerabilities/Risks & $\begin{array}{c}\text { Structural } \\
\text { (Engineering) } \\
\text { Disaster Risk } \\
\text { Reduction Options }\end{array}$ & $\begin{array}{l}\text { Nonstructural Disaster Risk } \\
\text { Reduction Options }\end{array}$ \\
\hline $\begin{array}{l}\text { Agriculture, } \\
\text { Natural } \\
\text { Resources, } \\
\text { and Rural } \\
\text { Development } \\
\text { (Example: } \\
\text { Floods) }\end{array}$ & $\begin{array}{l}\text { In relation to community } \\
\text { vulnerability: } \\
\text { Recurrent floods damage } \\
\text { crops and degrade land, } \\
\text { soil and rural infrastructure, } \\
\text { including irrigation and } \\
\text { drainage systems } \\
\text { Irrigation project encourages } \\
\text { use or development of } \\
\text { marginal and hazard-prone } \\
\text { lands, increasing community } \\
\text { exposure }\end{array}$ & $\begin{array}{l}\text { Increase resilience of } \\
\text { construction materials } \\
\text { against moisture and } \\
\text { salinity. } \\
\text { Increase design } \\
\text { standards of the } \\
\text { irrigation project, } \\
\text { including a higher } \\
\text { capacity drainage } \\
\text { system. }\end{array}$ & $\begin{array}{l}\text { Strengthen maintenance } \\
\text { systems and budgets for } \\
\text { irrigation infrastructure to } \\
\text { prevent clogging, waterlogging, } \\
\text { and salinity in most vulnerable } \\
\text { areas. } \\
\text { Strengthen water resource } \\
\text { management systems, } \\
\text { increasing resilience against } \\
\text { both floods and droughts. } \\
\text { Address land and water use } \\
\text { planning to protect watersheds } \\
\text { and flood retention. } \\
\text { Strengthen seasonal and } \\
\text { short-term weather forecasting } \\
\text { and crop advisory services for } \\
\text { farmers including the use of } \\
\text { weather forecast information. } \\
\text { Develop crop insurance. } \\
\text { Enhance on-farm water } \\
\text { management, including } \\
\text { cultivation practices that } \\
\text { reduce water requirements. } \\
\text { Diversify incomes of farming } \\
\text { households. } \\
\text { Invest in ecosystem-based } \\
\text { disaster risk management } \\
\text { (DRM) options, e.g., increasing } \\
\text { protective vegetative cover and } \\
\text { rehabilitating wetlands, ponds. }\end{array}$ \\
\hline
\end{tabular}




\begin{tabular}{|c|c|c|c|}
\hline Sector & Key Vulnerabilities/Risks & $\begin{array}{c}\text { Structural } \\
\text { (Engineering) } \\
\text { Disaster Risk } \\
\text { Reduction Options }\end{array}$ & $\begin{array}{l}\text { Nonstructural Disaster Risk } \\
\text { Reduction Options }\end{array}$ \\
\hline \multirow[t]{2}{*}{$\begin{array}{l}\text { Transport } \\
\text { (Example: } \\
\text { Earthquakes) }\end{array}$} & $\begin{array}{l}\text { In relation to project } \\
\text { investment: } \\
\text { Urban highway network } \\
\text { at medium risk from } \\
\text { earthquakes }\end{array}$ & $\begin{array}{l}\text { Adjust choice of } \\
\text { construction materials } \\
\text { and design standards } \\
\text { to enhance seismic } \\
\text { resilience. } \\
\text { Prioritize highway } \\
\text { elements for retrofitting } \\
\text { according to (i) } \\
\text { their importance to } \\
\text { the network, and } \\
\text { (ii) susceptibility to } \\
\text { damage and implement } \\
\text { structural measures } \\
\text { (e.g., installation } \\
\text { of shock absorbing } \\
\text { isolators and dampers } \\
\text { for bridges). }\end{array}$ & $\begin{array}{l}\text { Promote the design of } \\
\text { an integrated urban } \\
\text { transport disaster } \\
\text { response plan. } \\
\text { Strengthen highway } \\
\text { maintenance } \\
\text { system (including } \\
\text { maintenance } \\
\text { budgets) and } \\
\text { management. } \\
\text { Develop disaster risk } \\
\text { financing instruments } \\
\text { (e.g., insurance) } \\
\text { to support swift } \\
\text { reconstruction of } \\
\text { critical facilities. }\end{array}$ \\
\hline & $\begin{array}{l}\text { In relation to community } \\
\text { vulnerability: } \\
\text { High dependency on } \\
\text { highway/ car traffic for access } \\
\text { to city } \\
\text { Squatter settlements close to } \\
\text { highway bridges }\end{array}$ & & $\begin{array}{l}\text { Invest in traffic management } \\
\text { systems to monitor, control and } \\
\text { manage traffic flow and density } \\
\text { including provisions to quickly } \\
\text { close traffic routes and/or } \\
\text { facilitate access of emergency } \\
\text { services to victims. } \\
\text { Promote community-based } \\
\text { DRM in low-income/high-risk } \\
\text { areas adjacent to highway. }\end{array}$ \\
\hline
\end{tabular}




\begin{tabular}{|c|c|c|c|}
\hline Sector & Key Vulnerabilities/Risks & $\begin{array}{c}\text { Structural } \\
\text { (Engineering) } \\
\text { Disaster Risk } \\
\text { Reduction Options }\end{array}$ & $\begin{array}{l}\text { Nonstructural Disaster Risk } \\
\text { Reduction Options }\end{array}$ \\
\hline \multirow[t]{2}{*}{$\begin{array}{l}\text { Energy } \\
\text { (Example: } \\
\text { Floods and } \\
\text { landslides) }\end{array}$} & $\begin{array}{l}\text { In relation to project } \\
\text { investment: } \\
\text { Network of small-scale } \\
\text { hydropower and transmission } \\
\text { stations at medium risk of } \\
\text { damage from flooding and } \\
\text { landslides, including from } \\
\text { sedimentation damage to } \\
\text { hydropower plant turbines }\end{array}$ & $\begin{array}{l}\text { Prioritize critical power } \\
\text { installations and assets } \\
\text { for relocation and/ } \\
\text { or upgrading (e.g., } \\
\text { elevate critical power } \\
\text { installations on a strong } \\
\text { platform). } \\
\text { Adjust choice of } \\
\text { construction materials } \\
\text { to increase strength/ } \\
\text { resilience. } \\
\text { Apply or increase } \\
\text { risk sensitive design } \\
\text { standards. } \\
\text { Introduce redundancies } \\
\text { in the energy } \\
\text { distribution system } \\
\text { reducing disruption of } \\
\text { the power supply to } \\
\text { critical installations. } \\
\text { Construct sediment } \\
\text { settling basins and } \\
\text { check dams. }\end{array}$ & $\begin{array}{l}\text { Develop a risk-sensitive } \\
\text { operations and maintenance } \\
\text { system for the power plants. } \\
\text { In association with the above, } \\
\text { develop a monitoring and early } \\
\text { warning system to detect (i) } \\
\text { high levels of sedimentation } \\
\text { and (ii) hazard events. Include } \\
\text { communities in the design and } \\
\text { operation of the system (see } \\
\text { below). } \\
\text { Promote land-use practices in } \\
\text { the upstream areas of the basin } \\
\text { to control sediment inflows } \\
\text { (such as terraced farming, } \\
\text { ponds for storing rapid surface } \\
\text { runoff, low tillage). } \\
\text { Invest in ecosystem-based } \\
\text { buffers that reduce severity } \\
\text { of hazards (vegetative cover, } \\
\text { marshes, forests, etc.) }\end{array}$ \\
\hline & $\begin{array}{l}\text { In relation to community } \\
\text { vulnerability: } \\
\text { Communities to benefit from } \\
\text { the project live in remote } \\
\text { areas and have limited } \\
\text { access to services, including } \\
\text { emergency management } \\
\text { services }\end{array}$ & & $\begin{array}{l}\text { Promote community-based } \\
\text { disaster risk management and } \\
\text { response capacity, especially for } \\
\text { seasonal hazards. } \\
\text { Provide communities with } \\
\text { basic skills in maintenance } \\
\text { and emergency repair of } \\
\text { hydropower and electricity } \\
\text { infrastructure. } \\
\text { Invest in community } \\
\text { environmental management } \\
\text { options (e.g., increasing } \\
\text { protective vegetative cover } \\
\text { against floods and landslides). }\end{array}$ \\
\hline
\end{tabular}




\begin{tabular}{|c|c|c|c|}
\hline Sector & Key Vulnerabilities/Risks & $\begin{array}{c}\text { Structural } \\
\text { (Engineering) } \\
\text { Disaster Risk } \\
\text { Reduction Options }\end{array}$ & $\begin{array}{l}\text { Nonstructural Disaster Risk } \\
\text { Reduction Options }\end{array}$ \\
\hline & $\begin{array}{l}\text { In relation to project } \\
\text { investment: } \\
\text { Water supply and sewerage } \\
\text { installations and network, } \\
\text { including storage and } \\
\text { treatment facilities, at risk from } \\
\text { earthquakes and collateral } \\
\text { landslides }\end{array}$ & $\begin{array}{l}\text { Adjust choice of } \\
\text { construction materials to } \\
\text { increase resilience. } \\
\text { Apply or increase } \\
\text { risk-sensitive design } \\
\text { standards. } \\
\text { Create redundancies in } \\
\text { critical systems to buffer } \\
\text { loss of function. }\end{array}$ & $\begin{array}{l}\text { Strengthen urban emergency } \\
\text { management and postdisaster } \\
\text { recovery plans and capacities. } \\
\text { Develop disaster risk financing } \\
\text { instruments (e.g., insurance) to } \\
\text { support swift reconstruction of } \\
\text { critical facilities. }\end{array}$ \\
\hline $\begin{array}{l}\text { Water and } \\
\text { Other Urban } \\
\text { Infrastructure } \\
\text { and Services } \\
\text { (Example: } \\
\text { Earthquakes } \\
\text { and collateral } \\
\text { landslides) }\end{array}$ & $\begin{array}{l}\text { In relation to community } \\
\text { vulnerability: } \\
\text { Many settlements are informal } \\
\text { and have limited access to } \\
\text { services. Due to a lack of titles } \\
\text { and legal status, households } \\
\text { have little incentive to invest in } \\
\text { the resilience of their homes. }\end{array}$ & $\begin{array}{l}\text { Strengthen the resilience } \\
\text { of basic services } \\
\text { and infrastructure in } \\
\text { vulnerable settlements } \\
\text { facing moderate hazard } \\
\text { intensity. }\end{array}$ & $\begin{array}{l}\text { Raise awareness of disaster } \\
\text { risk among key stakeholders } \\
\text { including politicians, urban } \\
\text { planners, community leaders, } \\
\text { and groups. } \\
\text { Strengthen community-based } \\
\text { DRM in informal settlements } \\
\text { (including coping mechanisms in } \\
\text { earthquakes, search and rescue, } \\
\text { and first aid). } \\
\text { Promote ecosystem-based } \\
\text { disaster risk management (e.g., } \\
\text { bioengineering/vegetation on } \\
\text { critical slopes, prohibition of } \\
\text { occupation of green and safe } \\
\text { areas that can be used for } \\
\text { evacuation and shelter). }\end{array}$ \\
\hline
\end{tabular}

Note: The table is divided into structural and nonstructural activities that (i) protect project investments and (ii) protect at risk communities. Each sector is discussed in relation to a specific hazard, alternating between floods and earthquakes. Source: ADB. 


\section{Appendix 6: List of Sample Disaster Risk Management Indicators}

Sector

Agriculture

Energy

Transport

Urban development

\section{Disaster Risk Management as a Specific Component}

Farming households that have access to crop or livestock insurance increases by $\mathrm{xx} \%$ between $20 \mathrm{xx}$ and $20 \mathrm{xx}$

Number of power substations elevated above expected flooding levels increases by $\mathrm{xx} \%$ between 20xx and 20xx

Number of seismically retrofitted bridges is doubled between 20xx and $20 x x$

Number of medium- to high-risk settlements covered by early warning arrangements and an evacuation plan is doubled between $20 x x$ and $20 x x$

Source: ADB. 


\section{Disaster Risk Assessment for Project Preparation}

\section{A Practical Guide}

Disasters pose a significant threat to the sustainability of development investments. From 2007 to 2016 , disasters triggered by natural hazards caused average daily physical losses of $\$ 133$ million in the developing member countries (DMCs) of the Asian Development Bank (ADB) alone.

This practical guide provides technical advice on disaster risk assessment to facilitate the consideration of disaster risks in the design of development projects, seeking to ensure that disaster risks are properly identified and measures taken to reduce them where necessary. Disaster risk assessments can also help steer development investments to increase the disaster resilience of exposed and vulnerable communities more broadly.

\section{About the Asian Development Bank}

ADB's vision is an Asia and Pacific region free of poverty. Its mission is to help its developing member countries reduce poverty and improve the quality of life of their people. Despite the region's many successes, it remains home to a large share of the world's poor. ADB is committed to reducing poverty through inclusive economic growth, environmentally sustainable growth, and regional integration.

Based in Manila, ADB is owned by 67 members, including 48 from the region. Its main instruments for helping its developing member countries are policy dialogue, loans, equity investments, guarantees, grants, and technical assistance. 